UNIVERSIDADE DE SÃO PAULO

FACULDADE DE MEDICINA DE RIBEIRÃO PRETO

DEPARTAMENTO DE MEDICINA SOCIAL

DANIELA ELIAS GOULART DE ANDRADE

Prevalência de Sobrepeso e Obesidade em Crianças de

Escolas Públicas e Privadas do Ensino Fundamental da Cidade de Franca-SP e Alguns Fatores de Risco Associados.

Ribeirão Preto 
DANIELA ELIAS GOULART DE ANDRADE

\title{
Prevalência de Sobrepeso e Obesidade em Crianças de Escolas Públicas e Privadas do Ensino Fundamental da Cidade de Franca-SP e Alguns Fatores de Risco Associados.
}

\begin{abstract}
Dissertação apresentada ao Departamento de Medicina Social da Faculdade de Medicina de Ribeirão Preto da Universidade de São Paulo para obtenção do título de Mestre em Ciências Médicas.
\end{abstract}

Área de Concentração: Saúde na Comunidade Orientador: Prof. Dr. Amaury Lélis Dal Fabbro

\section{Ribeirão Preto}


AUTORIZO A REPRODUÇÃO E DIVULGAÇÃO TOTAL OU PARCIAL DESTE TRABALHO, POR QUALQUER MEIO CONVENCIONAL OU ELETRÔNICO, PARA FINS DE ESTUDO E PESQUISA, DESDE QUE CITADA A FONTE.

Ficha Catalográfica

Goulart de Andrade, Daniela Elias

Prevalência de Sobrepeso e Obesidade em Crianças de Escolas Públicas e Privadas do Ensino Fundamental da Cidade de Franca-SP e Alguns Fatores de Risco Associados / Daniela Elias Goulart de Andrade; Orientador: Amaury Lélis Dal Fabbro. Ribeirão Preto, 2006.

$$
\text { 73p.:il. ; 30cm }
$$

Dissertação (mestrado - Programa de Pós-Graduação em Medicina. Área de Concentração: Saúde na Comunidade) Faculdade de Medicina de Ribeirão Preto da Universidade de São Paulo.

1. Estado Nutricional 2. Obesidade Infantil 3. Hábitos Alimentares 4. Tipos de Escola. 


\section{FOLHA DE APROVAÇÃO}

Daniela Elias Goulart de Andrade

Prevalência de Sobrepeso e Obesidade em Crianças de Escolas Públicas e Privadas do Ensino Fundamental da Cidade de Franca-SP e Alguns Fatores de Risco Associados.

Dissertação apresentada ao Departamento de Medicina Social da Faculdade de Medicina de Ribeirão Preto da Universidade de São Paulo para obtenção do título de Mestre em Ciências Médicas.

Área de Concentração: Saúde na Comunidade

Aprovado em:

\section{Banca Examinadora}

Prof. Dr. Amaury Léllis Dal Fabbro

Instituição: Faculdade de Medicina de Ribeirão Preto da Universidade de São Paulo Assinatura:

\section{Prof $^{a}$. Dra ${ }^{\mathrm{a}}$. Daniela Saes Sartorelli}

Instituição: Faculdade de Medicina de Ribeirão Preto da Universidade de São Paulo Assinatura:

Prof ${ }^{a}$. Dra ${ }^{\mathrm{a}}$. Lúcia Helena Pelizer

Instituição: Universidade de Franca

Assinatura: 


\section{DEDICATÓRIA}

Dedico este trabalho:

AOS MEUS PAIS, JosÉ NILTON E DAYSE, E IRMÃOS, FABIANA, RODRIGO E DANILO, PELO APOIO, INCENTIVO E COMPREENSÃO. "SEM O APOIO DE VOCÊS NADA TERIA DADO CERTO".

Ao MEU MARIDO, CARLOS, QUE ESTÁ COMIGO A TODO O MOMENTO, INDEPENDENTE DO MOMENTO. 


\section{AGRADECIMENTOS}

Ao meu marido Carlos que compartilhou cada momento desde trabalho, do INÍCIO AO FIM COM PACIÊNCIA E COMPREENSÃO. SITUAÇÕES DIFÍCEIS SEMPRE VIVIDAS COM MUITO AMOR.

FÁ, MINHA IRMÃ, MUITO OBRIGADA, A SUA COLABORAÇÃO FOI DE EXTREMA IMPORTÂNCIA E É SEMPRE MUITO VALIOSA.

Ao meu orientador Prof Dr. Amaury que com muita sabedoria, Atenção e PACIÊNCIA ME AJUDOU A DESENVOLVER ESSE TRABALHO.

DANI E TERESA, MUITO OBRIGADA PELA “MÃOZONA” NO ABSTRACT.

Às AMIGAS PROF ${ }^{a}$ Dr. ${ }^{a}$ TELMA MARIA BRAgA COSTA E PROF ${ }^{a}$ Dr. ${ }^{a}$ RITA DE CÁsSIA Margarido Moreira. Agradeço a atenção especial que me deram, por me INCENTIVAREM A GOSTAR DE PESQUISA, E PRINCIPALMENTE POR ME ENSINAREM A faZer PESQUisa. "Mestres e Amigas".

À querida Prof ${ }^{a}$ Dr $^{a}$ LÚCIA Helena PElizer, DiRETORA do CURSO de NUTRIÇÃo DA UNIFRAN, PELA COMPREENSÃO E PRINCIPALMENTE COLABORAÇÃO NA COLETA DE DADOS DESTE TRABALHO.

Às ALUNAS DO CURSO DE NUTRICÃO DA UNIFRAN QUE ME AUXILIARAM NA COLETA DE

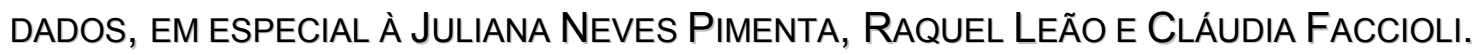


À AMIGA GISEle MASSAfERA, estéticA É COM Você!!!

À funcionária Rosane do Departamento de Medicina Social que tanto me AJUDOU NA ELABORAÇÃO DO BANCO DE DADOS. "VALEU Rô".

À bibliotecária Solange, do Departamento de Medicina Social que me AUXILIOU COM SABEDORIA COLOCAR ESSE TRABALHO NAS NORMAS.

Aos PROFESSORES DR. ANTÔNIO LUÍS, DR ${ }^{a}$ ALdAÍSA E DR ${ }^{a}$ TELMA PELAS SUGESTÕES TÃO BEM ACEITAS NA QUALIFICAÇÃO.

À NUTRICIONISTA DR a DANIELA SAES SARTORELLI QUE MUITO CONTRIBUIU COM AS SUGESTÕES NA PRÉ BANCA.

Á TODAS AS ESCOLAS E SEUS REPRESENTANTES QUE ME DEIXARAM COLETAR ESSAS INFORMAÇÕES TÃO ESSENCIAIS. E PRINCIPALMENTE AGRADEÇO A CADA ALUNO QUE ACEITOU PARTICIPAR DESSA PESQUISA. 
“Quem Quer Passar além do BOJ ADOR,

\section{Tem Que Passar Além da Dor."}

Fernando Pessoa. 


\section{RESUMO}

GOULART DE ANDRADE, D.E. Prevalência de Sobrepeso e Obesidade em Crianças de Escolas Públicas e Privadas do Ensino Fundamental da Cidade de Franca - SP e Alguns Fatores de Risco Associados. 2006. 73f. Dissertação (Mestrado) - Faculdade de Medicina de Ribeirão Preto, Universidade de São Paulo, Ribeirão Preto, 2006.

Nas últimas décadas houve aumento significativo na prevalência da obesidade nos países desenvolvidos e vem crescendo também naqueles em desenvolvimento, tornando-se um dos principais problemas de saúde pública. A importância do diagnóstico e tratamento da obesidade em fases precoces da vida justifica-se, pois ela favorece alterações metabólicas que se tornam mais graves quanto maior o grau de obesidade e o tempo de sua instalação. O objetivo deste trabalho é avaliar o estado nutricional de escolares do ensino fundamental de escolas da rede pública e privada da cidade de Franca-SP e conhecer a prevalência de sobrepeso/obesidade, investigando possíveis associações entre componente alimentar, atividade física e nível sócioconomico dos mesmos, fatores considerados como possíveis influentes da obesidade, tornando-se necessário intervir com um programa de educação alimentar antes que a doença se agrave. Foram avaliados 492 alunos de ambos os sexos com idades entre 6 e 10 anos matriculados da $1^{\mathrm{a}}$ a $4^{\mathrm{a}}$ séries do ensino fundamental de escolas particulares, estaduais e municipais da cidade de Franca-SP, através de avaliação nutricional com coleta de dados antropométricos (peso e altura) e aplicação de um questionário sobre hábitos alimentares, atividade física e condição sócio-econômica elaborado pelos pesquisadores. Foi encontrado que 59,6\% das crianças estudadas são eutróficas; $15,8 \%$ se encontram nas classificações de baixo peso e $24,6 \%$ foram classificadas como excesso de peso, onde 11,6\% possuem sobrepeso e 13,0\% obesidade. Os dados vão de encontro à literatura, porém, a prevalência da obesidade parece ser maior que os últimos achados. Houve uma associação do nível sócioconomico com a prevalência de excesso de peso, com predominância nas escolas particulares (37,4\%), em relação às escolas estaduais $(23,7 \%)$ e municipais $(18,9 \%)$ $(p=0,004)$. Destaca-se que $28,0 \%$ dos sujeitos obesos estão matriculados em escolas particulares. Das 492 crianças avaliadas, 56,5\% realizam apenas a prática desportiva oferecida no currículo escolar. Os sujeitos classificados como eutrófico/baixo peso realizam uma freqüência mais adequada de atividade física (68,6\%), se comparados com os classificados como sobreopeso/obesidade (34,4\%). No que se refere aos hábitos alimentares, a preferência alimentar de 38,4\% é de alimentos do grupo energético extra e $72,9 \%$ tem como alimentos que menos gostam aqueles do grupo de reguladores. A informação que o excesso de peso está instalado em aproximadamente $25 \%$ da população estudada, que o sedentarismo é a realidade da maioria das crianças, que a preferência em sua alimentação são os alimentos fontes de energia extra, enquanto, aqueles que são fontes de vitaminas, sais minerais e fibras são os de menor preferência, traz grande preocupação, tornando-se necessário desenvolver um programa de incentivo a prática de atividade e de reeducação alimentar com as crianças estudadas e suas respectivas famílias, com o objetivo de reduzir as taxas de obesidade encontradas e prevenir que esta instale nesta população.

Palavras-chaves: Estado Nutricional, Obesidade Infantil, Hábitos Alimentares, Tipos de Escola. 


\begin{abstract}
GOULART DE ANDRADE, D.E. Prevalence of overweight and obesity in private and public elementary school children in the city of Franca and some associate risk factors. 2006. 73f. Dissertação (Master) - Medicine School of Ribeirão Preto, University of São Paulo, Ribeirão Preto, 2006.
\end{abstract}

Over the last decades, the significant increase of the prevalence of obesity in developed and developing countries has become one of the most important public health problems. The relevance of the diagnostic and treatment of obesity during early ages is justified, because it contributes to metabolic changes that are more severe in higher obesity levels and earlier installation periods. The goal of this study was to evaluate eating habits, physical activity and social and economical environment of elementary school students, factors which possibly influence obesity and require intervention by means of an eating education program before the disease gets even worse. 492 students from $1^{\mathrm{a}}$ to $4^{\mathrm{a}}$ grades of private, local and state elementary schools were evaluated in Franca-SP, through nutritional assessment, collection of anthropometrical data (weight and height) and application of a survey about eating habits, physical activity and socioeconomic conditions developed by the examiners. It was noticed that $59.6 \%$ of the observed children had normal nutritional conditions; $15.8 \%$ were classified as underweight and 24.6 were classified as overweight, where $11.6 \%$ were considered overweight and $13.0 \%$, obese. The data confirm literature, although the prevalence of obesity seems to be higher than the last findings. It has been verified that, even without statistic association, in our sample the boys were more obese than girls, what has been corroborated by the literature. There was an association between the socioeconomic level and the prevalence of overweight, mostly in private schools (37.4\%) when comparing to state schools $(23.7 \%)$ and municipal schools $(18.9 \%)(p=0,004)$. It is important to highlight that $28.0 \%$ of obese subjects attend private schools. Among 492 children studied, 56.5\% practiced only the sport activities offered in the school program. The subjects who were classified as with normal nutritional conditions/ underweight used to practice physical activities in a more satisfactory frequency (68.6\%) if compared to the classified as overweight/obese (34.4\%). Regarding to eating habits, the eating preferences to $38.4 \%$ were provisions of the extra energetic group and $72.9 \%$ chose as the least appreciated the food belonging to the regulatory group. There was not an association between the quality of the food during the meals throughout the day, however this fact does not indicate that the children's feeding is adequate. The information that overweight is reflected in $1 / 4$ of the studied population, that sedentary lifestyle is a reality to most of the children, that their food preferences are meals with extra energetic supply, while, those who are vitamin suppliers, mineral supplement and fibers are less preferred, brings great concern, requiring the development of a program to motivate the practice of physical activity and eating reeducation with the studied children and their families, aiming at reducing the obesity rates and at preventing that it remains on this population.

Key words: Nutritional State, Childish Obesity, Eating Habits, School Kind. 


\section{LISTA DE FIGURAS}

Figura 1. Distribuição quanto ao Sexo dos Indivíduos Estudos $(n=492) . . \quad 33$

Figura 2. Distribuição dos Indivíduos quanto ao Tipo de Escola (n=492).. 34

Figura 3. Classificação do Estado Nutricional dos Sujeitos $(n=492) \ldots \ldots \ldots$

Figura 4. Relação entre a Classificação do Estado Nutricional dos Sujeitos (agrupado) e o Tipo de Escola $(p=0,004) \ldots \ldots \ldots \ldots \ldots \ldots . . . . . . . . .38$

Figura 5. Relação entre os Tipos de Escola e o Número de Indivíduos na Casa

Figura 6. Relação entre Atividade Física e o Estado Nutricional (agrupado) $(p=0,600)$

Figura 7. Relação entre Atividade Física e o Tipo de Escola $(p=0,028) \ldots 44$

Figura 8. Distribuição dos Grupos do Alimento Preferido pelos Sujeitos ..

Figura 9. Distribuição dos Grupos do Alimento que os Sujeitos Menos Gostam

Figura 10. Relação dos Grupos do Alimento Preferido e o Estado Nutricional de Sobrepeso e Obesidade

Figura 11. Relação dos Grupos do Alimento que Menos Gosta e o Estado Nutricional de Sobrepeso e Obesidade 


\section{LISTA DE TABELAS}

Tabela 1. Classificação do Estado Nutricional de acordo com as Medidas Antropométricas de peso e altura, para Percentil de IMC/idade/sexo .......................................................... 30

Tabela 2. Número de Alunos com Sobrepeso/obesidade em cada Tipo de Escola

Tabela 3. Categorias para a Freqüência de Atividade Física

Tabela 4. Número de Alunos com Sobrepeso/obesidade e a Freqüência de Atividade Física 


\section{SUMÁRIO}

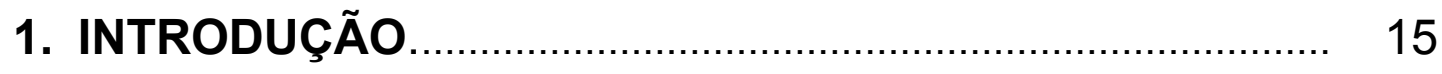

1.1 Conceituação de Obesidade .................................................... 15

1. 2 História da Obesidade ......................................................... 16

1. 3 Fatores que podem influenciar o surgimento da Obesidade ...... 18

1. 4 Riscos e morbidades associadas à Obesidade ........................ 20

1. 5 Tratamento …................................................................ 22

1. 6 Justificativa ................................................................. 23

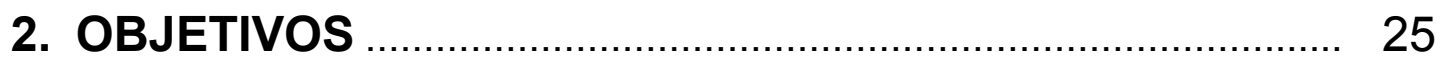

3. MATERIAL E MÉTODO ….................................................... 27

4. RESULTADOS E DISCUSSÕES …..................................... 33

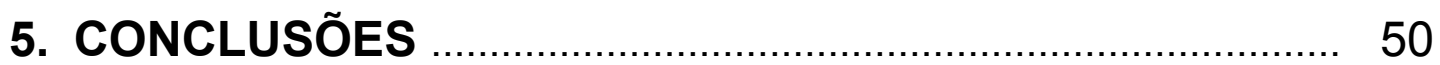

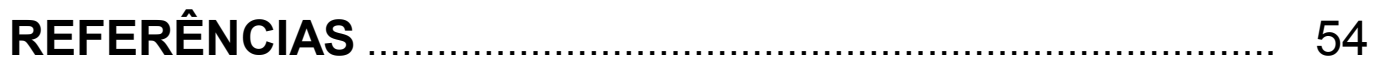

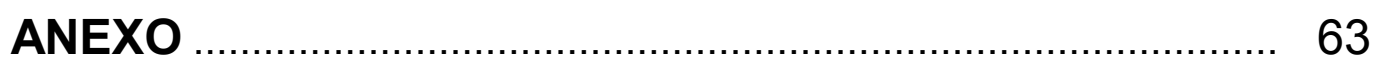

APÊNDICES $\quad 65$ 
INTRODUÇÃO 


\section{INTRODUÇÃO}

\subsection{Conceituação de Obesidade}

A etiologia da obesidade permanece sendo um problema ainda não totalmente resolvido. Embora detectada com facilidade, algumas formas específicas de obesidade, principalmente nos casos de obesidade simples, também classicamente denominada obesidade primária ou exógena, são decorrentes de um desequilíbrio entre ingestão alimentar e gasto calórico. A maioria dos casos (95 a 98\%) é deste tipo, e apenas um percentual muito baixo (2 a 5\%) tem como causas as síndromes genéticas, tumores ou distúrbios endócrinos (ESCRIVÃO e cols, 2000).

A conceituação clássica é que diversos mecanismos endócrinos reguladores e/ou metabólicos determinam uma alteração da homeostase, acarretando incremento de peso.

Um dos critérios utilizados para avaliar se a pessoa adulta é ou não obesa, é o índice de massa corporal, que se baseia na relação Peso/Altura² Se acima de $30 \mathrm{~kg} / \mathrm{m}^{2}$, o indivíduo já pode ser considerado obeso, ou se acima do Percentil 95, de acordo com a National Center for Health Statistics (NCHS, 2000) para crianças e adolescentes, com idades entre 0 e 20 anos. Em outro método para o diagnóstico da obesidade infantil, avaliado por medidas antropométricas, são utilizados o peso e a altura. Com estes valores calcula-se o índice Peso/Estatura (P/E), que é a relação entre o peso encontrado e o peso ideal para a idade ajustado pela altura, e o padrão de referência utilizado também é o NCHS. Para a criança considera-se sobrepeso quando o valor encontrado estiver entre 100 e $120 \%$, e obesidade quando ele for maior ou igual a $120 \%$.

A obesidade pode ser definida como uma doença resultante do acúmulo anormal ou excessivo de gordura sob a forma de tecido adiposo, de forma que possa resultar em prejuízo à saúde. É uma doença complexa, multifatorial, na qual ocorre uma sobreposição de fatores genéticos, comportamentais e ambientais. Suas múltiplas facetas constituem desafio 
em várias áreas do conhecimento humano, quer seja em endocrinologia, epidemiologia, nutrição ou terapêutica.

Trabalhos recentes mostram evidências de estreita relação entre as características qualitativas da dieta e o aparecimento de doenças crônicodegenerativas e estas constituem um problema prioritário de saúde pública e de segurança alimentar, tanto em países desenvolvidos quanto nos menos desenvolvidos, incluindo todas as faixas etárias, destacando o aumento entre crianças e adolescentes (BONOMO e cols, 2003).

Nos primeiros estudos sobre obesidade, observava-se maior freqüência em mulheres do que em homens, porém, estudos de inquéritos de 1974 e 1989 evidenciaram crescimento de 75 e 60\%, respectivamente, na proporção de homens e mulheres obesos no mundo (WHO, 1998).

Segundo Silva e cols (2003) em trabalho sobre a prevalência de sobrepeso em crianças pré-escolares de escolas particulares de Recife (PE) o sobrepeso foi encontrado em $27,0 \%$ em meninas e $17,6 \%$ em meninos, porém, quando observado a obesidade nesta população o encontrado foi $9,8 \%$ em meninas, e $13,0 \%$ em meninos. Atualmente novos trabalhos vêm comprovando o achado deste autor; em recente pesquisa do Instituto Brasileiro de Geografia e Estatística (IBGE, 2006) foi demonstrado que $18,0 \%$ dos adolescentes brasileiros do sexo masculino têm excesso de peso, já no sexo feminino o encontrado foi $15,4 \%$.

\section{2 História da Obesidade}

Durante muito tempo na história da humanidade o ganho de peso era visto como um sinal de saúde e prosperidade. Porém, hoje o acúmulo de gordura ou obesidade é considerado uma das doenças crônicas mais comuns, que afeta crianças, adolescentes e adultos, principalmente nos países desenvolvidos (PERL e cols, 1998), embora sua prevalência possa variar de grupo para grupo.

Um estudo realizado nas regiões abrangentes do Indian Health Service Area nos Estados Unidos em 1995 mostra a prevalência mínima de 26\% e 
máxima de 59\% em crianças indígena-americanas entre 5 e 17 anos de idade, utilizando-se o índice de massa corporal (IMC) acima do percentil 85 em diversas áreas do país (CABALLERO e cols., 1998). Outro estudo realizado no mesmo país, com inquéritos nos anos de 1965 e 1980 constatou que a obesidade nas crianças de 6 a 11 anos aumentou em 67\% entre os meninos e em $41 \%$ entre as meninas no período (DIETZ,1986).

No Brasil a situação não é diferente. Trabalho realizado no Nordeste brasileiro, entre 1980 - 2000 mostrou aumento nos valores de prevalência de sobrepeso e obesidade em adolescentes masculinos e a velocidade de incremento, em duas décadas, aumentou 4,5 vezes (VASCONCELOS; SILVA, 2003).

O que vem ocorrendo é a chamada inversão dos problemas nutricionais. A desnutrição infantil vem diminuindo se comparada com a prevalência de sobrepeso ou obesidade. Esta transição pode estar diretamente relacionada com a transição demográfica, que, no Brasil, foi acelerada no período de 1960-1980. A população era fundamentalmente rural (66\%) nos anos 1950 e, segundo dados do IBGE (2000), o país se tornou essencialmente urbano com mais de $80 \%$ da população residindo nas cidades (BATISTA-FILHO; RISSIN, 2003).

A característica do mercado brasileiro na época era voltada para o setor primário (agropecuária e extrativismo) e hoje os setores secundário e terciário são os maiores geradores de empregos, modificando a relação de geração de renda, estilos de vida e, especialmente, as demandas nutricionais das populações (BATISTA-FILHO; RISSIN, 2003).

Foi na primeira metade do século passado que a epidemiologia da nutrição tomou impulso, e os primeiros métodos de avaliação nutricional em populações passaram a ser desenvolvidos (WILLETT, 1998).

Na década de 1930, era usual atribuir à obesidade a denominação de "distúrbios de glândulas endócrinas". A partir das décadas de 1940 e 1950 é que uma aproximação de natureza psicológica passou a receber maior ênfase. Kahtalian (1992) sugere conceituá-la como processo psicossomático ou como expressão sintomática dos conflitos internos e externos que se realimentam como em um mecanismo de "feedback". A maioria dos 
pesquisadores concorda que a obesidade é um problema complexo e pode envolver fatores metabólicos, nutricionais, psicológicos e sociológicos. Provavelmente não é um transtorno isolado, mas uma gama de transtornos que têm o excesso de gordura como seu principal sintoma (RODIN, 1981).

\subsection{Fatores que podem influenciar o surgimento da Obesidade}

Segundo Oliveira e cols. (2000) o fator de risco mais importante para o aparecimento de obesidade na criança é a presença desta em seus pais, pela soma das influências genéticas e ambientais. Atkinson (1995) sugere que, quando ambos os pais são obesos, existe a probabilidade de $80 \%$ de que seus filhos também venham a ser; se apenas um dos pais é obeso esta probabilidade é de $40 \%$, e se os pais têm peso normal, é de $10 \%$.

No entanto, como colocam Oliveira e cols. (2000), somados à influência genética, estão os fatores culturais e familiares que, através da influência da aprendizagem, predispõe a que os filhos simplesmente imitem os hábitos alimentares de seus pais.

Ainda como fatores resultantes da interação entre genética e ambiente, sabe-se que o número e o tamanho de células adiposas, determinados geneticamente, também podem contribuir para a obesidade, pois o excesso alimentar pode, por sua vez, aumentar o tamanho dessas células, enquanto a privação pode diminuí-lo (ROLLAND-CACHERA e cols., 1984).

A atividade física habitual tem sido reconhecida como um componente importante de um estilo de vida saudável (GUERRA e cols., 2003). Quanto ao seu papel na gênese da obesidade, é sabido que pessoas sedentárias acumulam maior quantidade de gorduras. Uma criança atualmente gasta em média $600 \mathrm{Kcal}$ diárias a menos do que há 50 anos atrás. As atividades de recreação passaram a ser "dentro de quatro paredes"; uma criança assiste hoje, em média, 27hs de televisão por semana (ALVES, 2003). E, uma exposição de apenas 30 segundos a comerciais de alimentos é capaz de influenciar a escolha de crianças a determinado produto, o que mostra o 
papel da televisão no estabelecimento de hábitos alimentares (ALMEIDA; NASCIMENTO; QUAIOTI, 2002).

Dentre indivíduos com semelhante nível de ingestão alimentar, aqueles com limitada atividade física podem ganhar muito mais peso em relação a indivíduos de atividade intensa. A importância da atividade física foi demonstrada por Berkey e cols. (2000) que examinaram o papel da atividade e inatividade físicas e padrões dietéticos nas mudanças anuais de peso entre adolescentes e pré-adolescentes.

Fatores econômicos e sociais também têm sido apontados como determinantes muito importantes para a ocorrência da obesidade. De acordo com Marinho e cols. (2003), a obesidade é mais prevalente entre mulheres de classe sócio-econômica baixa do que entre as de condição mais elevada em países desenvolvidos. Em estudo recente, os autores encontraram que a obesidade se instalou em 19,8\% das mulheres residentes da zona urbana e em 23,4\% nas da zona rural. Parece, no entanto, que nos países em desenvolvimento as pessoas estão mais propensas a se tornar obesas, quanto mais alta for sua situação sócio-econômica (LOGUE, 1991). Todavia, a população de classe econômica baixa também vem apresentando este problema.

Marinho e cols. (2003) afirmam que na zona urbana o excesso de peso tem relação direta com o nível sócioconomico entre os homens e inversa entre as mulheres. Esses mesmos autores mostram os resultados da Pesquisa Nacional sobre Saúde e Nutrição (PNSN) em 1989, onde em ambos os sexos, na zona rural, a obesidade está diretamente relacionada a renda familiar.

A classe sócio-econômica pode influenciar a obesidade por meio da educação, da renda e da ocupação, resultando em padrões comportamentais específicos que afetam a ingestão calórica, gasto energético e taxa de metabolismo. O predomínio da obesidade no Brasil ocorre na classe sócio-econômica mais alta da população, embora ela ocorra nas diferentes faixas econômicas. A relação entre obesidade e classe sócio-econômica baixa é observada em países em desenvolvimento (MELLO e cols.; 2004). 
O nível sócioconomico interfere no poder de compra de alimentos e no acesso à informação, bem como pode estar associado à atividade física, constituindo-se, portanto, importante determinante da prevalência da obesidade (SILVA e cols., 2005).

Oliveira e Fisberg (2003) mostraram que, criança estudar em escola privada e ser unigênita, são fatores preditivos na determinação do ganho excessivo de peso, o que pode comprovar a influência do fator sócioconomico e do micro-ambiente familiar. De acordo com os autores, o acesso mais fácil aos alimentos ricos em gorduras e açúcares simples, assim como, o uso de computadores e videogames, em substituição à atividade física, poderiam explicar a maior prevalência da obesidade encontrada em estudantes de escolas particulares.

Os fatores genéticos, fisiológicos e metabólicos são importantes na gênese da obesidade; no entanto, as mudanças de estilo de vida e hábitos alimentares podem explicar este crescente aumento no número de indivíduos obesos (RODENBAUM; LEIBEL, 1998); (BRAY; POPKIN, 1998).

Em estudo realizado recentemente, esta prevalência aumentada se caracteriza em escolas públicas estaduais da cidade de São Paulo (SP), onde $10,29 \%$ dos meninos e $11,73 \%$ das meninas são obesos (SOTELO e cols., 2004).

Nas últimas décadas houve aumento significativo na prevalência de obesidade nos países desenvolvidos, em que ela se tornou um dos principais problemas de saúde pública. O Brasil tem sido considerado um país em transição nutricional em razão dos recentes aumentos na prevalência de obesidade e doenças crônicas na classe média, sendo importante identificar os fatores que influenciam as preferências nutricionais e alimentares desse grupo (DOYLE; FELDMAN, 1997).

\section{4 Riscos e morbidades associadas à Obesidade}

Existem dados, embora controversos, que sugerem que a obesidade se inicia na infância, ou melhor, que crianças obesas provavelmente serão 
adultos obesos. Fisberg (2004) afirma que a obesidade na infância e na adolescência tem como importância a possibilidade de manutenção na vida adulta. A época de transição da criança obesa para o adulto obeso pode ser variada. Sabe-se que $80 \%$ dos adultos que apresentam obesidade severa foram crianças ou adolescentes obesos (CABALLERO e cols., 1998). Se na infância a morbidade não é freqüente, na adolescência verifica-se a concomitância de fatores de risco, que levam a que, no adulto, a situação seja de risco, com aumento da mortalidade (FISBERG, 2004).

A preocupação com a obesidade é decorrente das conseqüências que acarreta no campo médico e psicológico, seja como "selo de invalidação pessoal", onde o indivíduo se torna descrente de sua capacidade de conviver e desempenhar suas funções na sociedade, seja como agravante de várias entidades clínicas com repercussões em diversos aparelhos: respiratório, circulatório, locomotor, etc. Coballero e cols. (1998) citam as evidências que sugerem que a obesidade durante a adolescência pode proporcionar longos e duradouros efeitos (diabetes mellitus, hipertensão arterial, dislipidemias e outros agravos), mesmo quando o peso corpóreo retorna ao normal depois desta fase.

Isto mostra a necessidade de intervenção já na idade escolar para se tentar reduzir a ocorrência crescente desta doença e suas possíveis conseqüências. De um modo geral, considera-se que, além do risco aumentado de morbi-mortalidade associado com a gordura corporal, o excesso de peso também pode afetar a qualidade de vida. Para a cultura atual, obesidade também pode ser um estigma social, já que as pessoas obesas geralmente são percebidas como indulgentes e sem força de vontade (Strauss, 2000).

Strauss (2000) alerta para o fato de que a obesidade infantil tem conseqüências prejudiciais para a auto-estima da criança, muito embora existam controvérsias a respeito de sua prevalência e magnitude. Pouco se sabe também a respeito dos efeitos sociais e emocionais da reduzida autoestima em crianças obesas. O autor encontrou que, ao longo dos quatro anos de estudo sobre auto-estima, as meninas obesas mostraram redução significativa nos níveis de auto-estima global, comparadas às não obesas. 
Reduções leves na auto-estima também foram observadas em meninos obesos comparados aos não obesos.

A baixa auto-estima em crianças obesas foi associada a taxas significativamente aumentadas de tristeza, solidão e nervosismo, comparadas com crianças cuja auto-estima aumentou ou permaneceu a mesma relacionada ao peso ou imagem corporal. Além disso, crianças obesas com níveis reduzidos de auto-estima ao longo dos quatro anos eram mais propensas a comportamentos de alto risco como fumar e consumir álcool quando comparadas com aquelas que não apresentaram mudanças na auto-estima (STRAUSS, 2000).

\section{5 Tratamento}

Oliveira e cols. (2000) afirmam que a importância do diagnóstico e tratamento da obesidade, em fases precoces da vida, justifica-se, pois, além de questões psicológicas e estéticas, ela favorece alterações metabólicas, que se tornam mais graves quanto maior o grau da obesidade e o tempo de sua instalação. A criança e o adolescente podem apresentar repercussões como dislipidemias, hipertensão arterial, alterações ortopédicas e posturais, dermatites, vulvovaginites e dificuldades respiratórias.

Como a obesidade é uma doença de etiologia multifatorial, é necessário, para o seu tratamento, uma abordagem multidisciplinar. A aderência do paciente à equipe é fundamental e importante, pois o tratamento geralmente é de longo prazo. Não se deve apontar apenas os riscos futuros da obesidade e sim avaliar as implicações atuais, ou seja, as conseqüências do excesso de peso que estão incomodando no momento (FISBERG, 2004).

Portanto, a necessidade de tratamento precoce é enfatizada pelo fato de que, quanto mais idade tiver a criança e maior for o excesso de peso, mais difícil será a reversão do quadro pelos hábitos alimentares incorporados e pelas alterações metabólicas instaladas (MAHAN; ESCOTTSTUMP, 1998). 
Considerando que o perfil alimentar da população está fortemente associado a aspectos nutricionais, culturais, demográficos e sócioconomicos, torna-se necessário melhor entendimento destes aspectos e os mecanismos das mudanças de comportamento alimentar e suas conseqüências (KUSHI e cols., 1988).

$\mathrm{Na}$ ciência da nutrição tratar a obesidade vai além de tratar o excesso de gordura no corpo de um indivíduo. Tendo em vista fatores cognitivos e emocionais associados ao aumento do consumo de alimentos, a mudança comportamental deve estar associada à mudança alimentar (FRANCISCHI, 2000). Segundo Wirth (1995) a dieta para perda de peso deve restringir a ingestão calórica total, visando uma diminuição total de energia, e não apenas de um nutriente.

Em alguns casos é necessária a redução da gordura corporal sem diminuir o peso, ocorrendo um aumento de massa muscular. A educação alimentar somada ao fator emocional e a prática de atividade física parece ser o caminho ideal para o tratamento e prevenção da obesidade (FRANCISCHI, 2000).

\subsection{Justificativa}

Estudos epidemiológicos atuais sobre indicadores de obesidade na infância estão surgindo e percebe-se que, na grande maioria, são restritos a países desenvolvidos. Para que se tenha a idéia da real importância dessa condição em sociedades em desenvolvimento, torna-se necessário a realização de novos estudos populacionais no Brasil, avaliando a prevalência desta condição em diferentes grupos sócioconomicos, e estabelecendo suas inter-relações com os hábitos alimentares, psicossociais e atividade física nestes indivíduos, a fim de que se possa intervir com um programa de educação alimentar evitando o agravamento desta doença e de problemas decorrentes dela. 
OBIETIVOS 


\section{OBJETIVOS}

\subsection{Objetivo Geral}

Este trabalho tem por objetivo avaliar o estado nutricional de escolares do ensino fundamental de escolas da rede pública e privada da cidade de Franca-SP e conhecer a prevalência de sobrepeso/obesidade.

\subsection{Objetivos Específicos}

Investigar possíveis associações entre a prevalência de sobrepeso/obesidade e

- Tipo de Escola;

- Atividade física e

- Componente alimentar. 
MATERIAL EMÉTODO 


\section{MATERIAL E MÉTODO}

Este trabalho consiste em Estudo epidemiológico do tipo transversal (estudo de prevalência) de crianças com idades entre 6 e 12 anos, matriculadas em escolas públicas (estadual e municipal) e privadas, para avaliar o estado nutricional das mesmas e os possíveis fatores que contribuem para o surgimento e/ou agravamento da obesidade.

1. Local do Estudo. Escolas de ensino fundamental de $1^{a}$ à $4^{a}$ séries da rede pública e privada da cidade de Franca-SP.

2. População de Referência. Escolares do ensino fundamental de $1^{\mathrm{a}}$ à $4^{\mathrm{a}}$ séries das escolas públicas e privadas da cidade de Franca-SP, com idades entre 6 e 12 anos, de ambos os sexos.

No total, a cidade de Franca possui 11 escolas municipais com 8.056 alunos, 20 escolas estaduais com 9.945 alunos e 19 escolas particulares com 3.283 alunos, totalizando 21.284 alunos matriculados nas $1^{\mathrm{a}}, 2^{\mathrm{a}}, 3^{\mathrm{a}}$ e $4^{\mathrm{a}}$ séries. As escolas particulares estão localizadas em vários bairros da cidade, e para freqüentá-las é necessário o pagamento de uma mensalidade. A maioria das escolas estaduais localiza-se em bairros mais centrais, são normalmente escolas mais antigas, freqüentadas por alunos com intermediário nível sócioconomico; por outro lado, as escolas municipais estão mais distribuídas na periferia, e abrange indivíduos com menores condições sócio-econômicas.

3. População de Estudo. Escolares do ensino fundamental de $1^{\mathrm{a}}$ à $4^{\mathrm{a}}$ séries das escolas públicas e privadas da cidade de Franca-SP, com idades entre 6 e 12 anos, de ambos os sexos, selecionados por um processo de amostragem e que preenchem os critérios de inclusão. 
4. Critérios de Inclusão.

- Estar matriculado nas escolas sorteadas;

- Ter o Termo de Consentimento Livre e Esclarecido assinado pelos pais ou responsáveis;

- Concordar em participar do estudo;

- No caso das meninas, não ter iniciado a puberdade (relato da menarca).

- No caso dos meninos, presença de pêlos axilares (relato).

5. Critérios de Exclusão. Para as meninas, aquelas que iniciaram a puberdade. Para os meninos, presença de pêlos axilar.

6. Amostragem. Foi realizada em 3 fases: amostragem por conglomerados (escolas e classes) em dupla etapa; amostragem estratificada por sexo e uma amostragem sistemática dos alunos nas classes.

Para a realização da pesquisa, foi solicitado autorização para os diretores das escolas privadas sorteadas para a realização da pesquisa. Para as escolas estaduais foi solicitado à Dirigente Regional de Ensino da cidade de Franca (Apêndice A), e para as municipais, esta autorização foi dada pela Secretária da Educação da cidade de Franca (Apêndice B).

Foi obtida a lista das escolas públicas (municipais e estaduais) e particulares registradas na Delegacia de Ensino de Franca-SP e o número de alunos matriculados entre $1^{\mathrm{a}}$ e $4^{\mathrm{a}}$ séries do ensino fundamental.

Para a escolha dos sujeitos, foi utilizado o método de amostragem estratificada, ou seja, usou-se a porcentagem correspondente ao número de alunos de cada tipo de escola (municipal, estadual e particular) para determinar o número de sujeitos de cada tipo de escola a ser estudado. Foi realizado sorteio das escolas, e nestas, sorteio das classes, pelo método de amostragem por conglomerado. Nas classes sorteadas realizou-se amostragem estratificada mantendo a mesma proporção dos sexos existente na população de estudo, e por fim, sortearam-se os alunos dentro destas classes, através de amostragem sistemática. 
Foi então, enviado aos pais dos alunos sorteados o Termo de Consentimento Livre e Esclarecido (TCLE) - CONEP conforme a resolução 196 (Apêndice C) e uma Carta de Esclarecimentos, explicando o estudo e propondo uma intervenção nutricional visando melhores hábitos alimentares e de vida para seus filhos.

7. Cálculo do tamanho mínimo amostral. Utilizou-se o aplicativo Epi-Info 6.0, onde:

$$
P+Q=100 \%
$$

(P) Proporção estimada (na literatura) de crianças com sobrepeso/ obesidade: $12 \%$

(Q) Proporção de crianças sem sobrepeso/obesidade: 88\%

(d) Erro amostral: 3\%

Intervalo de Confiança de 95\%

(z) variável normal reduzida: 1,96

Fórmula:

$$
d=z \cdot \sqrt{P \cdot Q / n}
$$

$$
\mathrm{n}=470 \text { indivíduos }
$$

8. Variáveis do Estudo. Foram estudadas as seguintes variáveis: sexo; idade; peso e altura; nível sócioconomico; atividade física; atividades recreacionais; preferências alimentares; aversões alimentares.

9. Procedimento. Estudo Piloto: primeiramente, um estudo piloto para testar o questionário de hábitos alimentares e psicossociais foi realizado. Quinze crianças, escolhidas aleatoriamente na cidade de Ribeirão Preto$\mathrm{SP}$, foram submetidas ao questionário. Este por sua vez, foi respondido com facilidade pelas crianças e as informações foram verificadas com os pais ou responsáveis dos mesmos a fim de avaliar a veracidade das 
informações. Nesta etapa verificou-se que tais informações eram compatíveis entre si.

Para iniciar a coleta de dados deste trabalho, conforme descrito anteriormente, foi feito contato com os pais dos sujeitos sorteados e mediante a autorização dos mesmos, iniciou-se a aplicação dos questionários, bem como a antropometria. Os dados de identificação foram coletados nos cadastros de matrícula de cada criança.

As tomadas de medidas antropométricas (peso e altura) foram realizadas no período de aula dos sujeitos em uma sala isolada de interferência. Os critérios de classificação do estado nutricional estão descritos na tabela 1.

10. Critérios para Classificação do Estado Nutricional

Tabela 1 - Classificação do estado nutricional de acordo com as medidas antropométricas de peso e altura, para Percentil de IMC/idade/sexo.

\begin{tabular}{lll}
\hline & \multicolumn{1}{c}{ Classificação } & Percentil \\
\hline 1 & Eutrófico & $\mathrm{P} 15-85$ \\
2 & Baixo Peso & $<\mathrm{P} 5$ \\
3 & Risco para Baixo Peso & $\mathrm{P} \mathrm{5}-15$ \\
4 & Sobrepeso & $\mathrm{P} 85-95$ \\
5 & Obesidade & $\geq \mathrm{P} 95$
\end{tabular}
Frisancho (1990)

Foi aplicado nas crianças um questionário de hábitos alimentares e psicossociais (Apêndice D) elaborado pelos pesquisadores, nas mesmas condições, livre de interferências. Este é composto por 24 questões que abrangem as variáveis anteriormente descritas de forma clara e de fácil 
compreensão pelas crianças e foi aplicado pela pesquisadora e/ou entrevistadores devidamente treinados.

11. Análise de Dados: A estatística descritiva compreendeu o cálculo de freqüência percentual e testes estatísticos de associação entre variáveis categóricas $\left(\mathrm{X}^{2}\right)$. Foram consideradas significantes as diferenças com $p \leq$ 0,05. Os dados foram analisados usando o aplicativo Epilnfo 6.0 (CDC, 1994). 
RESULTADOS E DISCUSSÕES 


\section{RESULTADOS E DISCUSSÕES}

Foram estudadas 492 crianças com idades entre 6 e 12 anos, sendo 238 indivíduos $(48,4 \%)$ do sexo masculino e $254(51,6 \%)$ do sexo feminino, conforme representado na Figura 1.

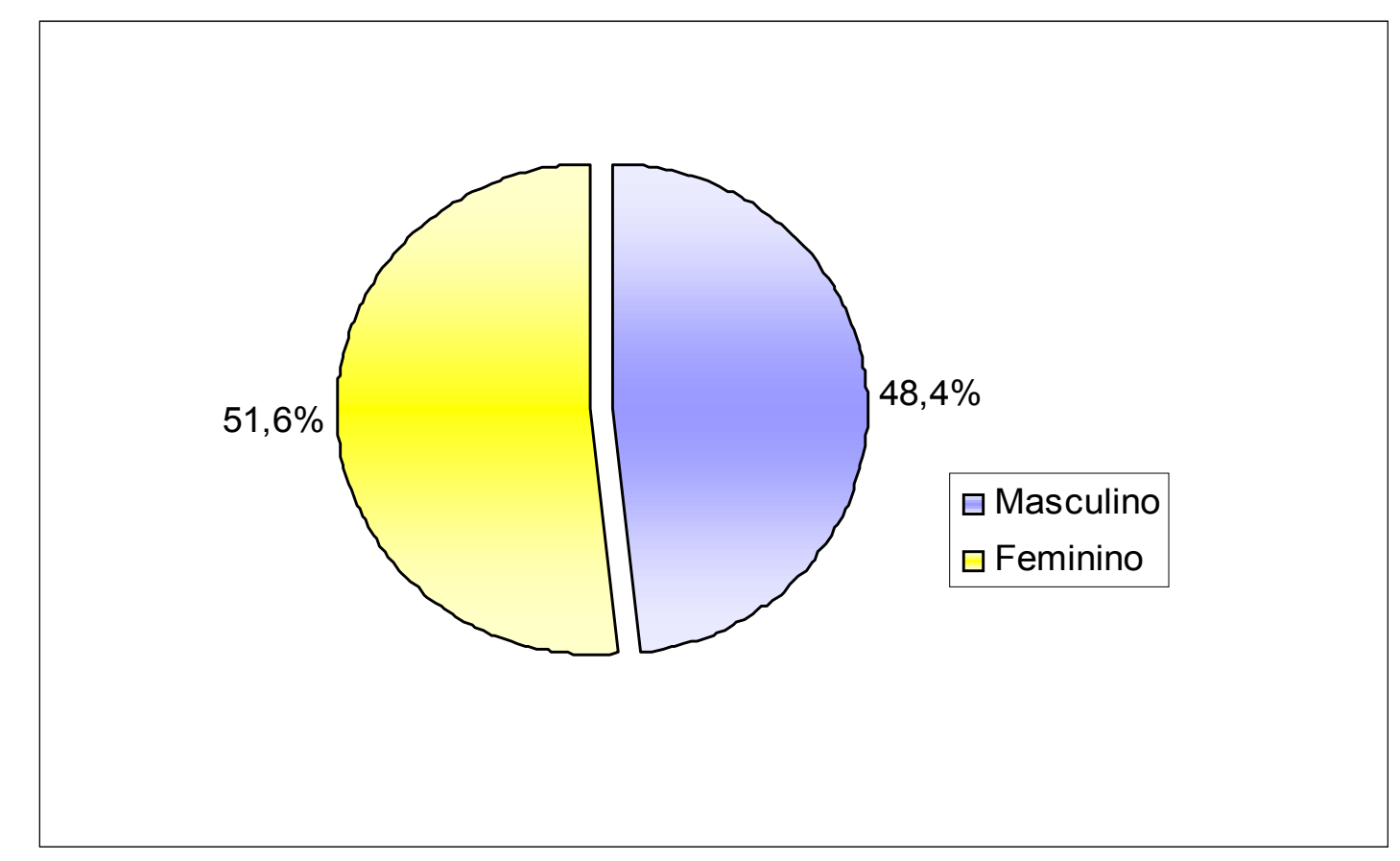

Figura 1. Distribuição quanto ao Sexo dos Indivíduos Estudados ( $n=492$ )

Quanto ao tipo de escola em que as crianças estudam, encontrou-se que 91 indivíduos (18,5\%) freqüentam escolas particulares, 169 (34,3\%) freqüentam escolas municipais e $232(47,2 \%)$ estudam em escolas estaduais (Figura 2). 


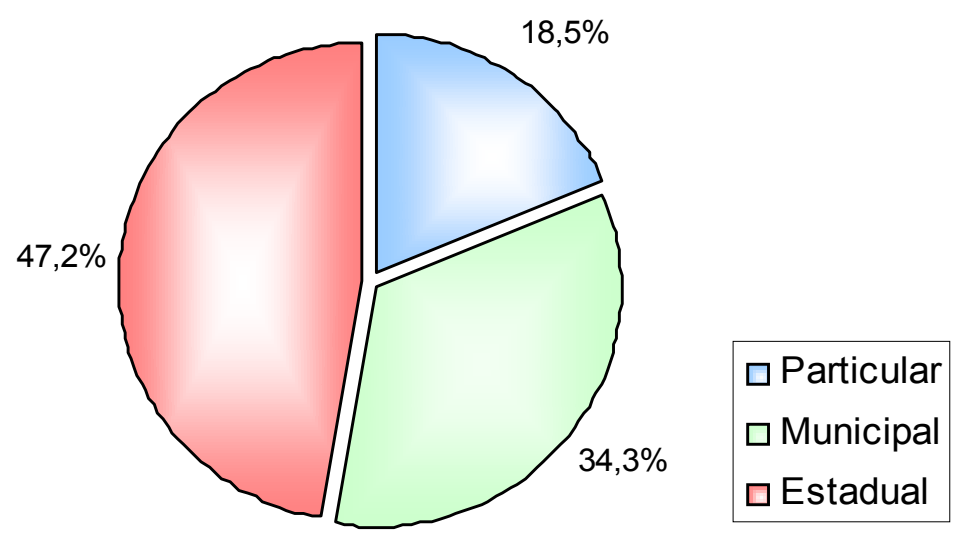

Figura 2. Distribuição dos Indivíduos quanto ao Tipo de Escola $(n=492)$.

Com o intuito de conhecer o perfil antropométrico da população estudada, foi calculado o Índice de Massa Corporal (IMC) da população total, e o parâmetro utilizado de acordo com o sexo foi de Percentil de IMC/idade/sexo e organizado em classes quanto ao estado nutricional conforme o padrão de referência do NCHS (2000) e classificação de Frisancho (1990). A escolha de classificar os sujeitos por Frisancho (1990) se deu ao fato de que neste método existe mais uma categoria, risco para baixo peso (Percentil entre 5 -15) se comparada a classificação da Organização Mundial da Saúde de 1995, sendo possível encontrar as crianças em risco nutricional.

Os resultados obtidos em relação ao IMC indicam que a maioria das crianças é considerada normal $(59,6 \%)$, porém a porcentagem de crianças com excesso de peso $(24,6 \%)$ é maior que a encontrada para a classificação baixo peso ou risco para baixo peso (15,8\%). O valor encontrado para sobrepeso é de $11,6 \%$ (57crianças) e a obesidade apareceu em 13,0\% (64 crianças). Já para a subnutrição foram encontrados $8,1 \%$ (40 crianças) com baixo peso e $7,7 \%$ (38 crianças) com risco para baixo peso. A Figura 3 demonstra esses valores. 


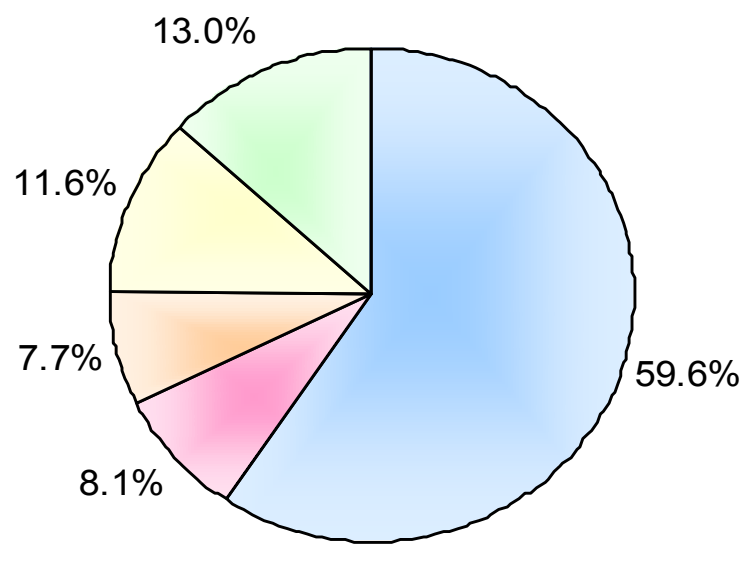

\section{$\square$ Eutrófico}

$\square$ Baixo Peso

$\square$ Risco para baixo peso

$\square$ Sobrepeso

$\square$ Obesidade

Figura 3. Classificação do Estado Nutricional dos Sujeitos ( $n=492)$.

Monteiro (2000) afirma que a subnutrição, embora ainda relevante, particularmente em crianças de baixa renda, vem diminuindo sua prevalência.

A maioria dos dados encontrados na literatura, até poucos anos atrás, caracterizava a população carente brasileira como desnutrida; porém Monteiro (2000) sugere que o Brasil vem rapidamente substituindo o problema da escassez pelo problema do excesso dietético. É importante ressaltar aqui, que é necessário verificar se esses excessos dietéticos de fato oferecem à população os nutrientes essenciais para manter o bom funcionamento do organismo, ou somente oferecem altas concentrações de alguns destes nutrientes, como por exemplo, gordura ou carboidrato (açúcares), apresentando um desequilíbrio de uma boa nutrição, favorecendo assim graves prejuízos nutricionais.

Cerqueira e cols (2003) demonstraram em seu estudo na cidade de Feira de Santana-BA que a prevalência de sobrepeso e obesidade em escolares foi de $9,3 \%$ e $4,4 \%$ respectivamente, não havendo diferença significativa entre os sexos. 
Em Florianópolis (SC), Soar e cols (2004) encontraram prevalência de $17,9 \%$ de sobrepeso e $6,7 \%$ de obesidade em escolares de 7 a 9 anos de escolas públicas.

Em nosso estudo, quanto ao estado nutricional é possível avaliar que os achados são semelhantes aos estudos citados anteriormente, onde ocorre um importante aumento em relação ao sobrepeso e obesidade em escolares. Foi observado que $24,6 \%$ da população se encontram com excesso de peso e destes, $11,6 \%$ apresentam sobrepeso e $13 \%$ foram classificados como obesos se comparados com a população de referência (NCHS, 2000).

Talvez a diferença na prevalência em relação ao trabalho de Cerqueira e cols (2003) se dê pela localização das cidades estudadas. Sabe-se que a região sudeste possui maiores condições de aquisição e de escolha de alimentos pelos indivíduos do que a região nordeste, independente da qualidade nutricional do mesmo. No estudo de Soar e cols (2004) a prevalência total de excesso de peso $(24,6 \%)$ é igual ao encontrado neste trabalho $(24,6 \%)$. Isso se dá pelo fato da região sul apresentar condições sócio-econômicas mais semelhantes à região sudeste. Este dado reforça a relação da condição sócioeconômica e estado nutricional da população brasileira.

Ainda comparando ao estudo de Soar e cols (2004), mesmo observando que as taxas de excesso de peso são iguais a esse estudo, cabe ressaltar que a prevalência de obesidade foi maior (13\%) neste estudo se comparado ao realizado em Florianópolis (6,7\%).

Com relação ao tipo de escola, o estado nutricional de eutrofia (normalidade) é predominante. O total é de $59,6 \%$ sendo que nas escolas particulares a eutrofia encontra-se em $52,7 \%$ dos indivíduos, nas municipais esse valor é de $60,9 \%$ e nas estaduais está em $61,2 \%$ das crianças estudadas, podendo verificar uma diferença de $8,5 \%$ entre escolas particulares e estaduais e de $8,2 \%$ entre escolas particulares e municipais.

As escolas municipais apresentam maior índice de baixo peso $(12,4 \%)$, porém risco para baixo peso predomina nas estaduais (9,1\%). É importante ressaltar que os índices de baixo peso e risco para baixo peso se encontram em menores valores nas escolas particulares, 5,5\% e 4,4\% respectivamente. 
Quanto à ocorrência de sobrepeso, há predominância nas particulares com o índice de $14,3 \%$. Nas municipais o valor encontrado foi de $10,7 \%$ e nas estaduais $11,2 \%$.

A obesidade apresenta um valor alarmante nas escolas particulares: $23,1 \%$ dos sujeitos são obesos. Não se pode dar menos importância ao observado nas escolas municipais e estaduais; os valores encontrados respectivamente para a obesidade nestas escolas foram: $8,3 \%$ e $12,5 \%$ $(p=0,013)$.

Para melhor visualização, a amostra foi redividida em duas classificações: eutróficos e baixo peso (classificação 1, 2 e 3 para estado nutricional) e excesso de peso ou sobrepeso/obesidade (classificação 4 e 5 para estado nutricional).

$\mathrm{Na}$ figura 4 é possível verificar que a associação continua positiva $(p=0,004)$ para prevalência de excesso de peso e tipo de escola, e que a maioria em relação ao número de alunos por escola com sobrepeso/obesidade, se encontra nas escolas particulares, com valor intermediário nas estaduais, e menor valor nas municipais, indo de encontro com o critério de classificação de nível sócioconomico dos sujeitos por tipo de escola.

Santos (2002) estudou por análise de Regressão Linear Multivariada (IMC como variável dependente) uma população de adolescentes da cidade de Ribeirão Preto - SP na faixa etária de 10 a 16 anos da rede pública e privada de ensino, e não encontrou associação significante entre o estado nutricional dos sujeitos e os estratos sócioconomicos dos bairros onde suas escolas estão localizadas. A diferença com este trabalho pode estar relacionada à faixa etária dos sujeitos e as diferenças de poder aquisitivos das duas cidades estudadas. 


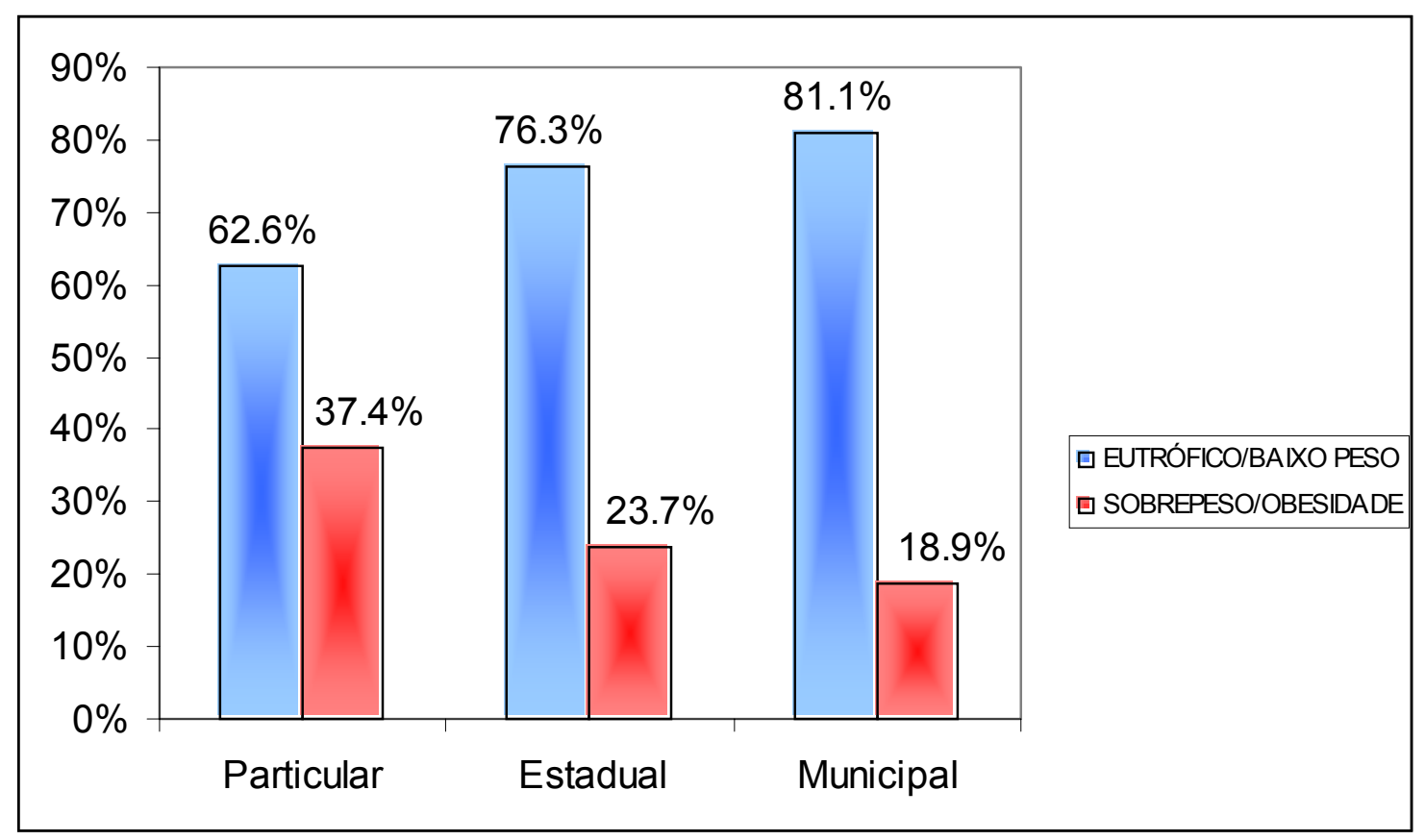

Figura 4. Relação entre a Classificação do Estado Nutricional dos Sujeitos (agrupado) e o Tipo de Escola $(p=0,004)$.

A Tabela 2 demonstra que se a avaliação for feita inversamente, ou seja, analisar os sujeitos classificados com sobrepeso/obesidade em cada tipo de escola, ainda é possível afirmar que a maioria se encontra nas escolas particulares onde dos 91 sujeitos matriculados, 37,4\% estão nesta categoria; dos 232 alunos das estaduais, 23,7\% e dos 169 alunos matriculados nas municipais, $18,9 \%$ são sobrepeso ou obesidade.

Tabela 2 - Número de Alunos com Sobrepeso/obesidade em cada Tipo de Escola

\begin{tabular}{lll}
\hline Escola & $\mathbf{N}^{\circ}$ de alunos & $\mathbf{N}^{\circ}$ de alunos com \\
& matriculados & sobrepesolobesidade
\end{tabular}

$\begin{array}{lccc}\text { Particular } & 91 & 34 & 37,4 \\ \text { Municipal } & 169 & 32 & 18,9 \\ \text { Estadual } & 232 & 55 & 23,7 \\ \text { TOTAL } & 492 & 121 & 24,6\end{array}$


Em relação ao IMC, verificou-se que a população masculina apresenta índices de sobrepeso e obesidade mais elevados que a feminina, porém, a associação não foi estatisticamente significante $(p=0,868)$. $O$ excesso de peso foi encontrado em $26,4 \%$ dos meninos (13,0\% sobrepeso e $13,4 \%$ obesidade); nas meninas os valores foram menores, $22,8 \%$, onde $10,2 \%$ apresentaram sobrepeso e $12,6 \%$ obesidade.

Esses dados corroboram com o encontrado na literatura, onde, Oliveira e cols. (2000), citam que em estudo realizado no Brasil, houve uma maior prevalência de obesidade masculina $(42,5 \%)$ em relação à feminina $(40,6 \%)$. Giugliano e Melo (2004) também comprovam essa mudança em seu estudo, quando a obesidade prevalece em $1 \%$ a mais nos meninos em relação às meninas.

No que se refere à escolaridade do chefe de família, não foi possível avaliar as informações coletadas, pois $46,3 \%$ das crianças não souberam informar com certeza essa variável.

Quanto à ocupação do chefe de família, encontrou-se que $46,1 \%$ dos sujeitos são trabalhadores da produção de bens e serviços industriais conforme a Classificação Brasileira de Ocupações (CBO) do Ministério do Trabalho e Emprego (2002). Isso se dá provavelmente devido à característica econômica da cidade de Franca, que tem como alicerce as fábricas de calçados que emprega em vários setores da produção um grande número de trabalhadores. Em segundo lugar o mercado varejista emprega 13,0\% dos chefes de família.

Em terceiro lugar, o setor calçadista volta a empregar 9,8\% dos chefes de família atuando na parte administrativa das empresas da cidade.

É importante ressaltar que aproximadamente 10\% das crianças não souberam informar a ocupação do chefe de família.

Em relação ao número de pessoas que moram na mesma casa da criança estudada, foi encontrado que em $52,6 \%$ dos lares residem cinco ou mais indivíduos contando com a criança, e, por outro lado $1 \%$ das crianças mora apenas com mais uma pessoa.

A Figura 5 mostra a diferença da constituição de lar entre os tipos de escolas estudadas; nas particulares, $23,1 \%$ dos lares são compostos por três indivíduos que moram na casa, contando com a criança e $41,89 \%$ são 
compostos por quatro indivíduos. Nas municipais, $65,1 \%$ dos lares são compostos por cinco ou mais indivíduos e apenas $0,6 \%$ é residido pela criança e mais uma pessoa. Já nas estaduais, a freqüência também é maior para os lares com cinco ou mais indivíduos $(50,9 \%)$, seguido de quatro indivíduos com $35,3 \%$ ( $p=0,0002$ ). Para a relação de estado nutricional (agrupado) e o número de pessoas que moram na mesma casa, não houve associação $(p=0,12)$.

Portanto, o número elevado de pessoas residindo na mesma casa é maior nas escolas estaduais e municipais em relação às particulares. Esse fato pode ser um indicador que reforça as diferenças sócio-econômicas dos sujeitos matriculados em cada um dos tipos de escolas.

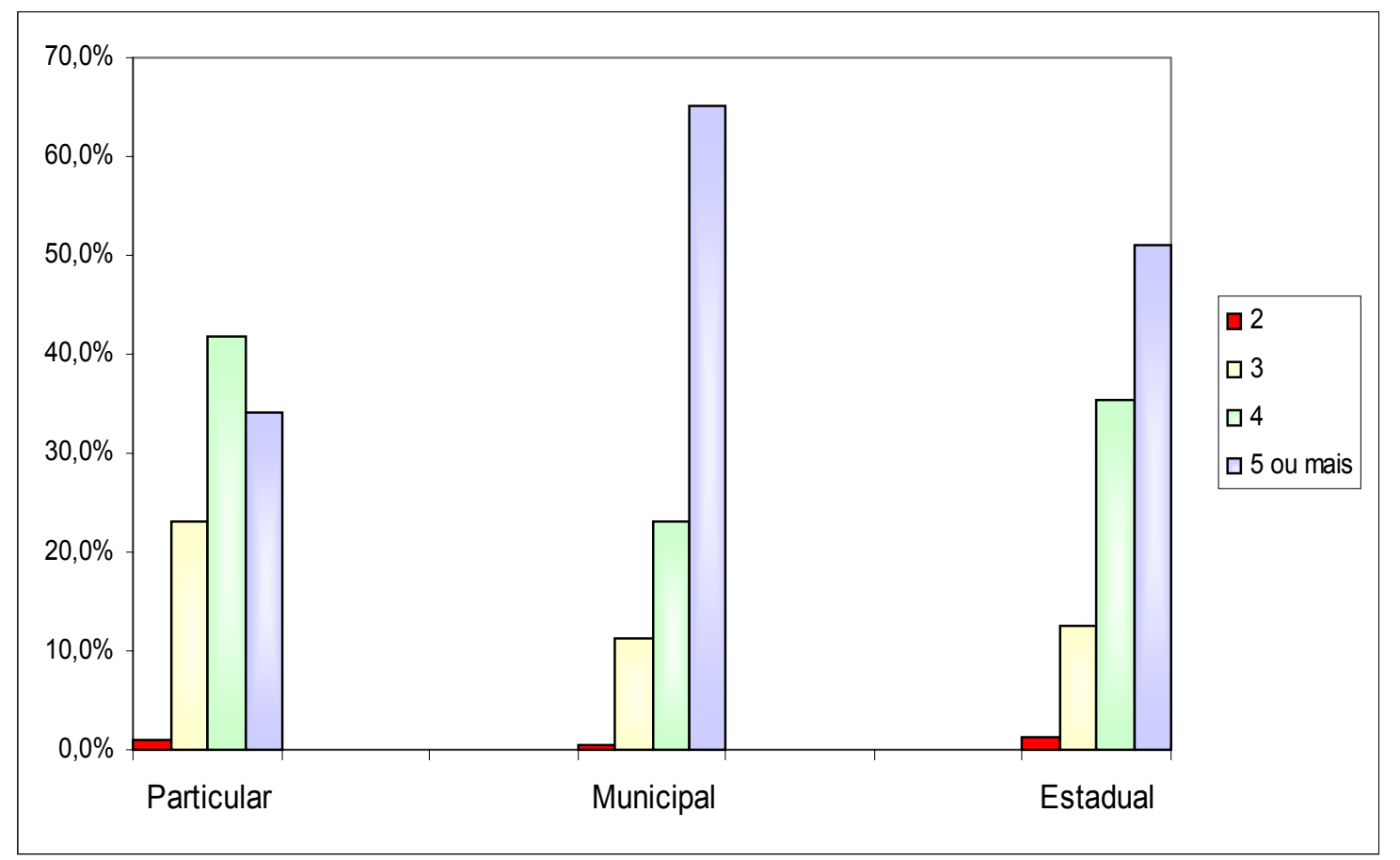

Figura 5. Relação entre os Tipos de Escola e o Número de Indivíduos na Casa.

Quanto ao número de pessoas que reside na casa e trabalha, foi encontrado que, em $25,6 \%$ dos lares, pelo menos um indivíduo trabalha e em $51,2 \%$ trabalham duas pessoas. A informação que três pessoas trabalham na 
casa é de $15,0 \%$ dos entrevistados; os outros $8,2 \%$ representam quatro ou mais trabalhadores ativos nos lares.

Neste estudo, observou-se que $56,5 \%$ das crianças estudadas realizam atividade física apenas uma vez na semana. Essa atividade é desempenhada na escola como parte das exigências do currículo escolar, nem sempre com aulas de esporte propriamente dito, e sim na maioria das vezes, brincadeiras recreacionais (jogar bola, etc.), ou seja, a criança que relatou praticar atividade uma vez na semana se referia a essa atividade.

Mesmo não encontrando associação significativa entre sobrepeso/obesidade e atividade física, não se pode deixar de lado o grande número de evidências sobre a sua importância para todos os indivíduos, em qualquer idade, sexo, cor, como amplamente citado na literatura.

Como a maioria da população estudada é considerada sedentária pelos padrões de recomendação, é necessário intervenção e estímulo para que essa prática seja inserida no cotidiano e se torne um hábito de vida dessas crianças.

Se agruparmos a freqüência de atividade conforme mostra a tabela $3 \mathrm{em}$ 3 categorias (inadequada: não realizam ou realizam apenas atividades do currículo escolar, regular: 2 ou 3 vezes na semana e adequada: 4 ou mais vezes na semana), temos que $62,6 \%$ das crianças se encaixam na primeira categoria, $30,3 \%$ na segunda e apenas $7,1 \%$ na categoria adequada para freqüência de atividade física.

Tabela 3 - Categorias para a Freqüência de Atividade Física
Categoria
Inadequada
Regular
Adequada

Freqüência de Não realizam ou Realizam 2 ou 3 Realizam 4 ou

\begin{tabular}{lll} 
atividade & apenas atividades do vezes na semana & mais vezes na \\
física & currículo escolar & semana \\
\hline
\end{tabular}

Para a freqüência de atividade física não foi encontrada associação $(p=0,600)$ com o estado nutricional. Na figura 6 é possível visualizar que a 
freqüência de atividade dos indivíduos com excesso de peso e eutrofia/baixo peso são parecidas quando analisada as freqüências entre si.

Para classificação de freqüência de atividade física irregular encontrou-se que 235 indivíduos (76,3\%) são classificados como eutrofia/baixo e 73 sujeitos $(23,7 \%)$ têm sobrepeso ou obesidade, totalizando 308 sujeitos. As 149 crianças que realizam atividades 2 ou 3 vezes na semana são, na sua maioria, classificadas como eutrofia/baixo peso $(75,2 \%)$, para sobrepeso/obesidade o valor é de $24,8 \%$. Trinta e cinco crianças que realizam atividades 4 ou mais vezes na semana são $68,6 \%$ de eutrofia/baixo e $34,4 \%$ de sobrepeso/obesidade.

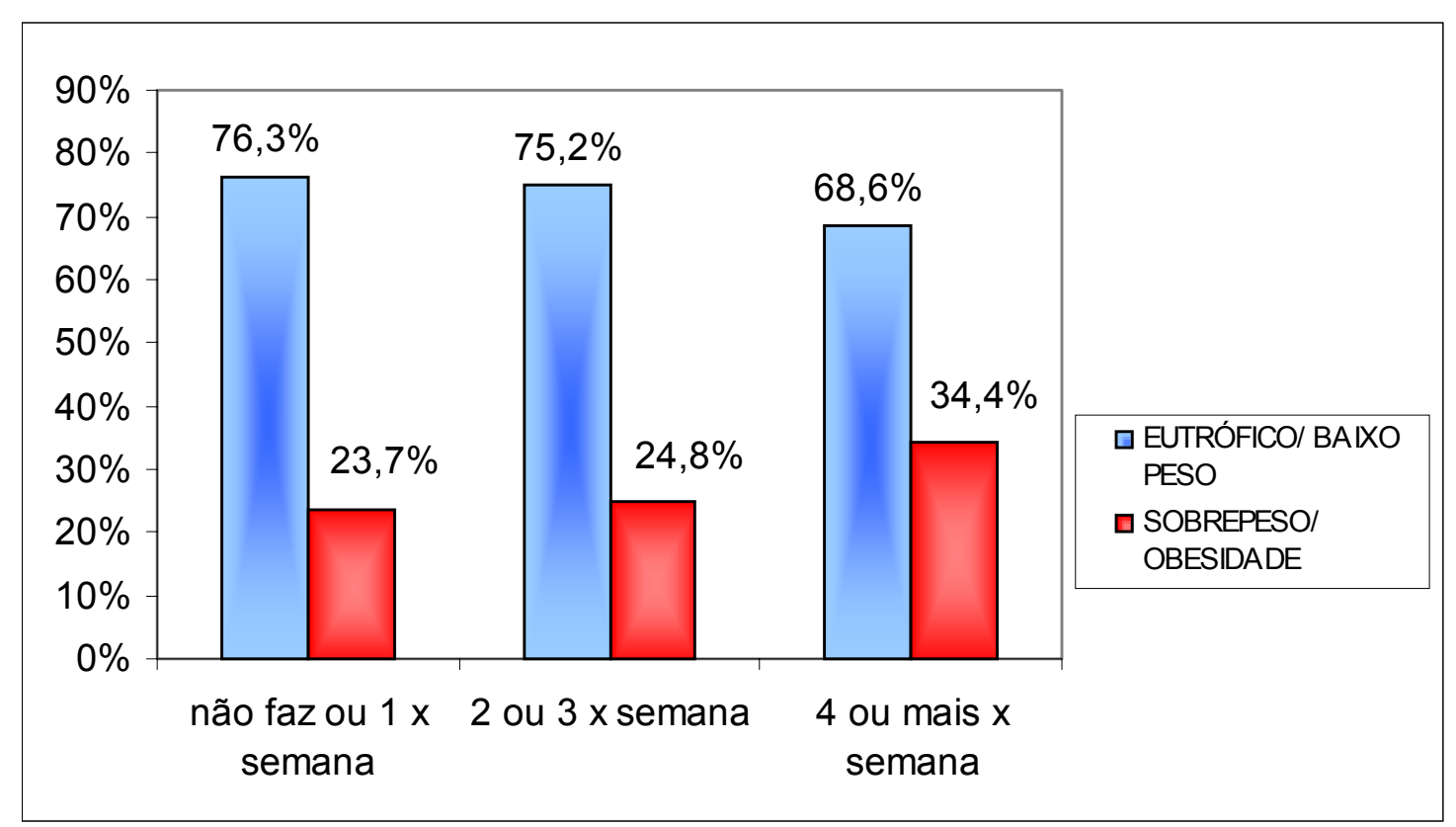

Figura 6. Relação entre a Atividade Física e o Estado Nutricional (agrupado) $(p=0,600)$.

É importante ressaltar que quando foi analisada a freqüência de atividade física apenas das crianças com sobrepeso e obesidade encontrou-se que apenas $9,1 \%$ dos mesmos têm a freqüência adequada (Tabela 4). 
Tabela 4 - Número de Alunos com Sobrepeso/obesidade e a Freqüência de Atividade Física

\begin{tabular}{lcc}
\hline $\begin{array}{l}\text { Freqüência de } \\
\text { atividade física }\end{array}$ & $\begin{array}{l}\mathbf{N}^{\circ} \text { de alunos com } \\
\text { sobrepeso/obesidade }\end{array}$ & (\%) \\
\hline Inapropriada & 73 & 60,3 \\
Regular & 37 & 30,6 \\
Adequada & 11 & 9,1 \\
TOTAL & 121 & 100 \\
\hline
\end{tabular}

Ao observar a relação entre freqüência de atividade física e o tipo de escola que a criança estuda, encontrou-se que os alunos das escolas estaduais fazem atividade física inapropriada em maior número (48\%) se comparadas à escola municipal $(37,7 \%)$ e à particular (14,3\%). Para a freqüência regular de atividade física os alunos que mais se encontram nesta categoria são os das escolas estaduais (45\%), seguidos das escolas municipais $(29,5 \%)$ e das escolas particulares $(25,5 \%)$. Observando a atividade física apropriada, as crianças das escolas particulares e municipais apresentam a mesma porcentagem $(25,7 \%)$ e a escola com melhor qualidade de atividade física é a estadual com $48,6 \%$ dos sujeitos (Figura 7). É importante demonstrar que a maior freqüência de atividade física apareceu nas escolas estaduais $(47,2 \%)$, seguidas das municipais $(34,3 \%)$ e das particulares $(18,5 \%)$. 


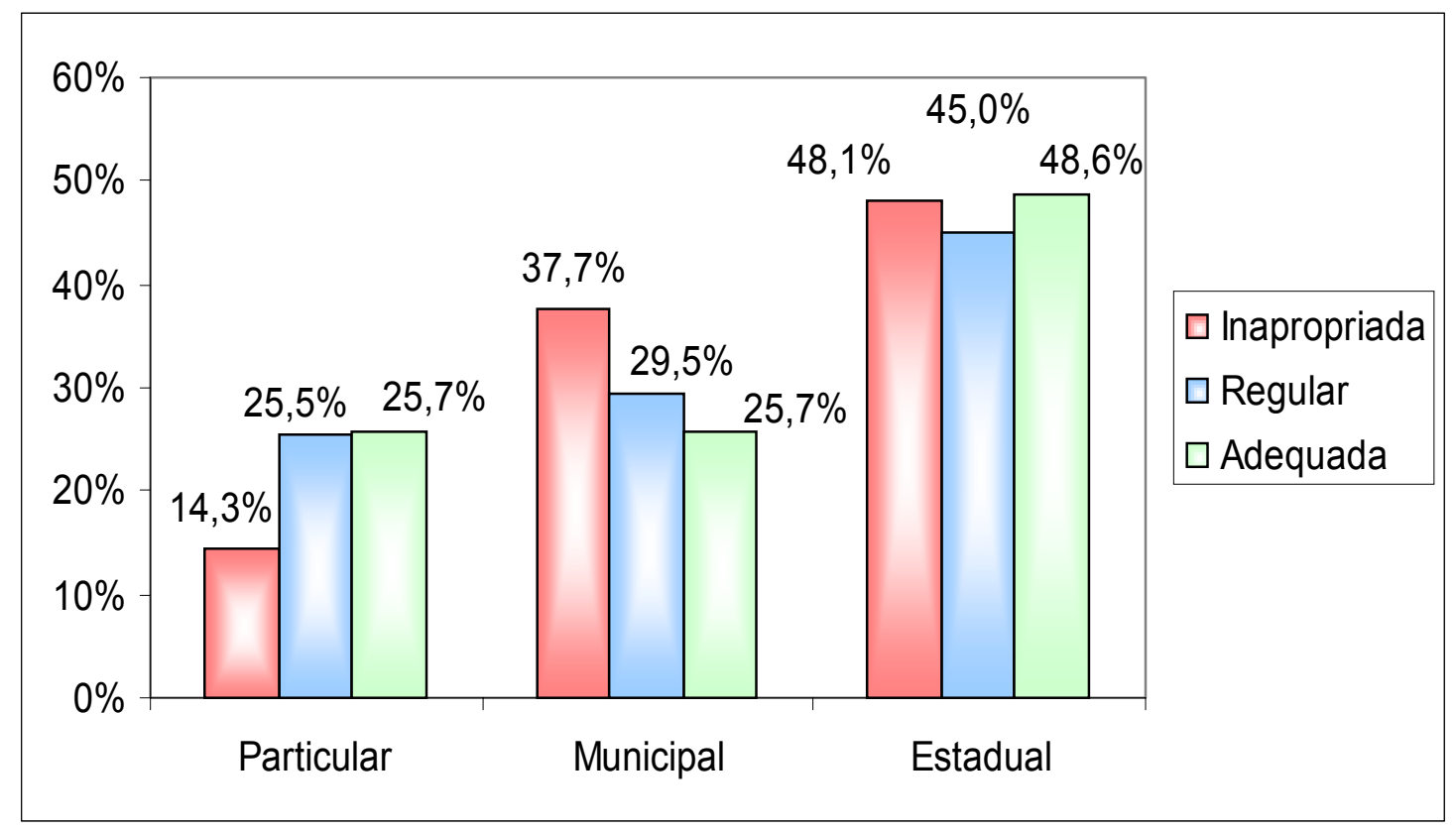

Figura 7. Relação entre a Atividade Física e o Tipo de Escola $(p=0,028)$

$\mathrm{Na}$ amostra observada verificou-se que a baixa porcentagem de atividade física praticada é referente à maioria da população, independente do estado nutricional. $O$ sexo dos sujeitos também não mostrou associação com a freqüência de atividade física $(p=0,126)$.

Berkey e cols. (2000) descrevem em trabalho recente que mudanças (aumentos) anuais de peso estão positivamente associadas ao aumento no consumo calórico e ao tempo de inatividade recreacional (TV, vídeos e jogos), e ainda com relação à freqüência de atividade física diminuída, apenas no sexo feminino houve aumento de IMC.

As atividades recreacionais mais prevalentes nesta população estudada foram: brincar dentro de casa, jogar videogame ou computador e assistir televisão $(65,2 \%)$; os outros $34,8 \%$ são representados pelas crianças que brincam na rua, arrumam a casa, ou trabalham. Porém, não se observou associação com a prevalência de sobrepeso/obesidade, independente do sexo $(p=0,668)$. Entre as crianças, $68,9 \%$ fazem menos de 2 horas por dia esse tipo de atividade; os outros $31,1 \%$ a fazem por mais de 2 horas diárias. Porém, não se observou associação com o sobrepeso/obesidade $(p=0,591)$. 
A alimentação e a atividade física influenciam na saúde seja de maneira combinada ou cada uma em separado. Assim, enquanto os efeitos da alimentação e da atividade física em saúde podem interferir no caso da obesidade, a atividade física possui benefícios adicionais independentes da nutrição e da dieta alimentar, havendo riscos nutricionais consideráveis que não guardam relação com a obesidade. A atividade física é fundamental para melhorar a saúde física e mental das pessoas (OMS, 2001).

Os governos desempenham um papel fundamental para criar com parceiros civis, um segmento que potencialize e impulsione mudanças no comportamento das pessoas, das famílias e das comunidades para que estas adotem decisões positivas em relação à alimentação saudável e a realização de atividades físicas que thes permitam melhorar suas vidas (OMS, 2001).

Abordando os dados referentes à alimentação dos sujeitos, quando questionado aos mesmos sobre a preferência ou aversão alimentar, foi considerado o primeiro alimento a ser respondido e então classificado pela pesquisadora nos respectivos grupos de nutrientes que o mesmo pertencia.

Independente do estado nutricional encontrou-se que a maioria $(38,4 \%)$ tem como preferência alimentar alimentos do grupo dos energéticos extras (açúcares, doces e óleos), seguido do grupo dos carboidratos (27\%) (Figura 8).

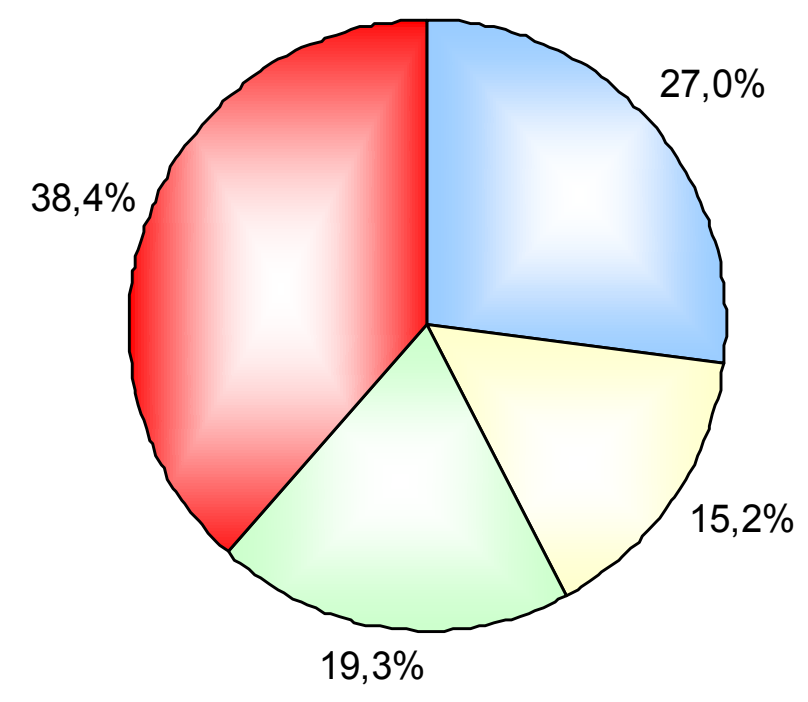

$\square$ Energéticos

$\square$ Construtores

$\square$ Reguladores

$\square$ Energéticos extras

Figura 8. Distribuição dos Grupos do Alimento Preferido pelos Sujeitos. 
Já em relação à resposta quanto ao alimento que menos gosta, a figura 9 mostra que o item que mais apareceu foi o referente aos alimentos reguladores (verdura, legume e frutas), com $72,9 \%$ das crianças; em seqüência as fontes de proteína são os alimentos menos aprovados pelas crianças com 16,3\%.

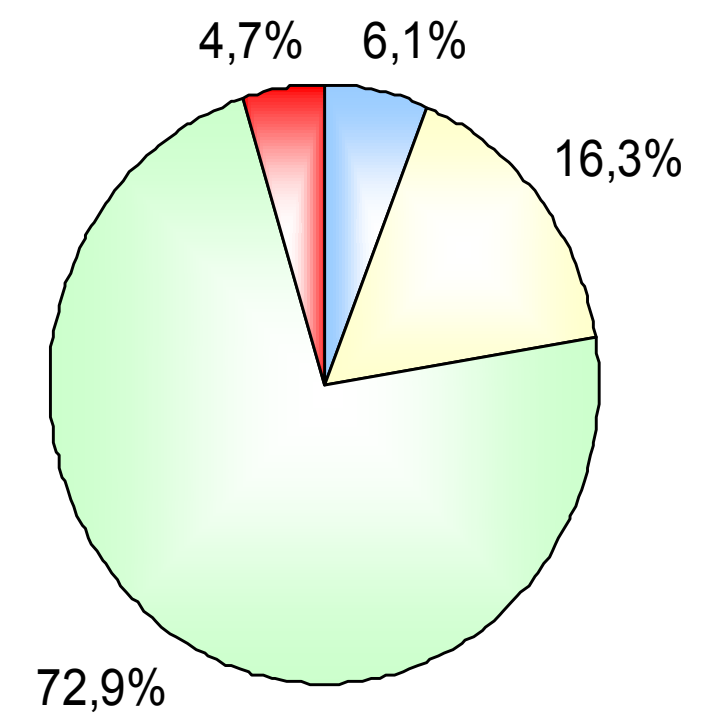

$\square$ Energéticos

$\square$ Construtores

$\square$ Reguladores

$\square$ Energéticos extras

Figura 9. Distribuição dos Grupos do Alimento que os Sujeitos Menos Gostam.

Embora não tenha havido associação positiva entre alimento preferido e estado nutricional, foi possível observar que a grande maioria tem preferência alimentos fontes de energia extra para compor suas refeições; por outro lado se observou que os alimentos do grupo reguladores, ou seja, fontes de vitaminas, sais minerais e fibras, foram os escolhidos por $72,9 \%$ dos alunos como os alimentos que eles menos gostam. Esse dado não afirma que o consumo alimentar das crianças seja baseado nesta informação; apenas um relato de opinião.

Analisando apenas as crianças com sobrepeso ou obesidade encontrouse que $38 \%$ (46 indivíduos) preferem os alimentos representados pelo grupo guloseima; em seguida, 28 sujeitos $(23,1 \%)$ preferem alimentos fontes de 
carboidratos, 25 ou $20,7 \%$ preferem aqueles fontes de proteína e por último com $18,2 \%$ dos sujeitos encontrou-se a preferência por alimentos fontes de vitaminas, fibras e sais minerais (Figura 10).

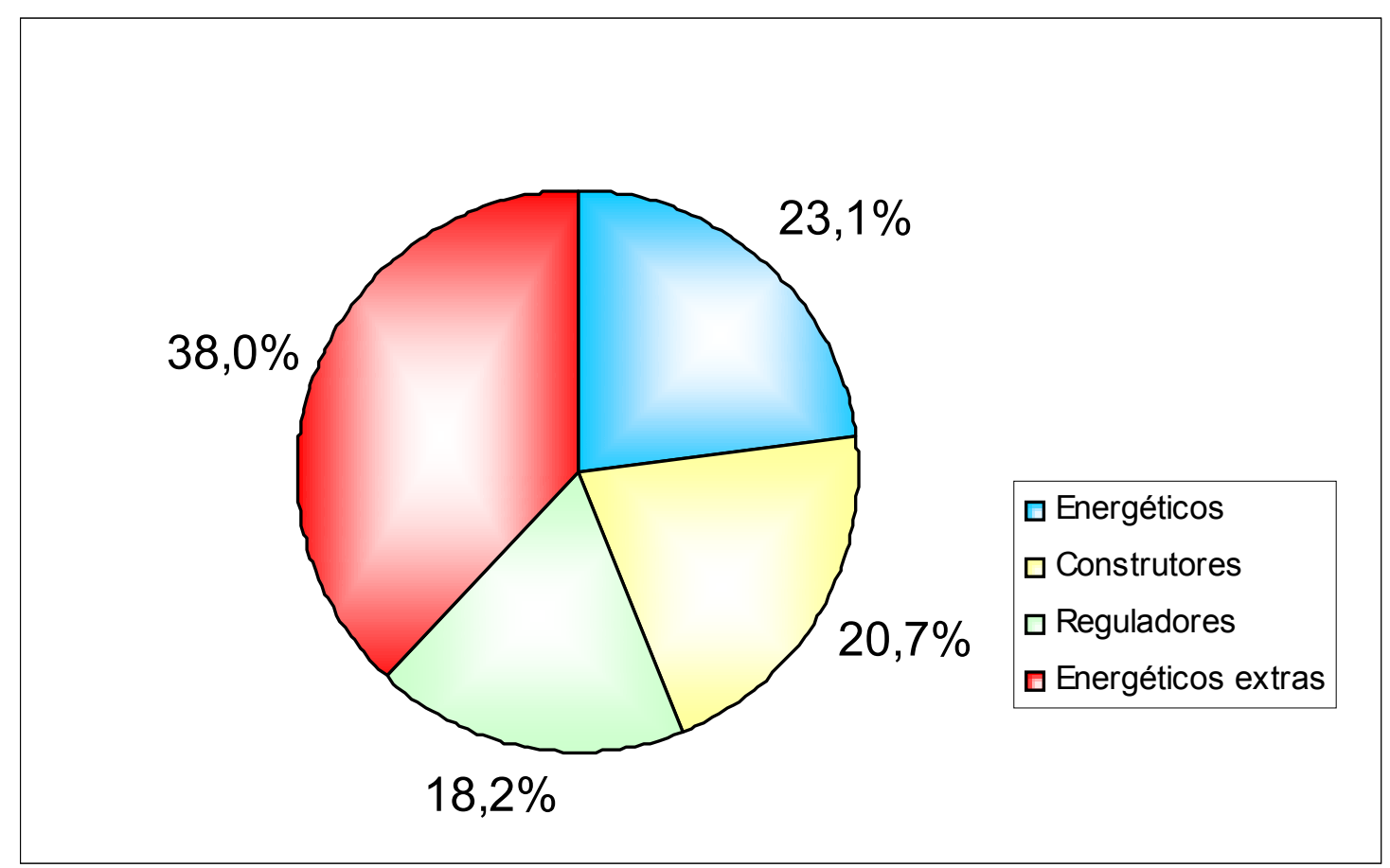

Figura 10. Relação dos Grupos do Alimento Preferido e o Estado Nutricional de Sobrepeso e Obesidade.

A figura 11 demonstra a relação dos sujeitos que possuem sobrepeso ou obesidade e os alimentos menos preferidos. Essa informação é bastante semelhante com a avaliação geral dos sujeitos, ou seja, parece não haver diferença entre as preferências e a aversões alimentares entre obesos e não obesos. 


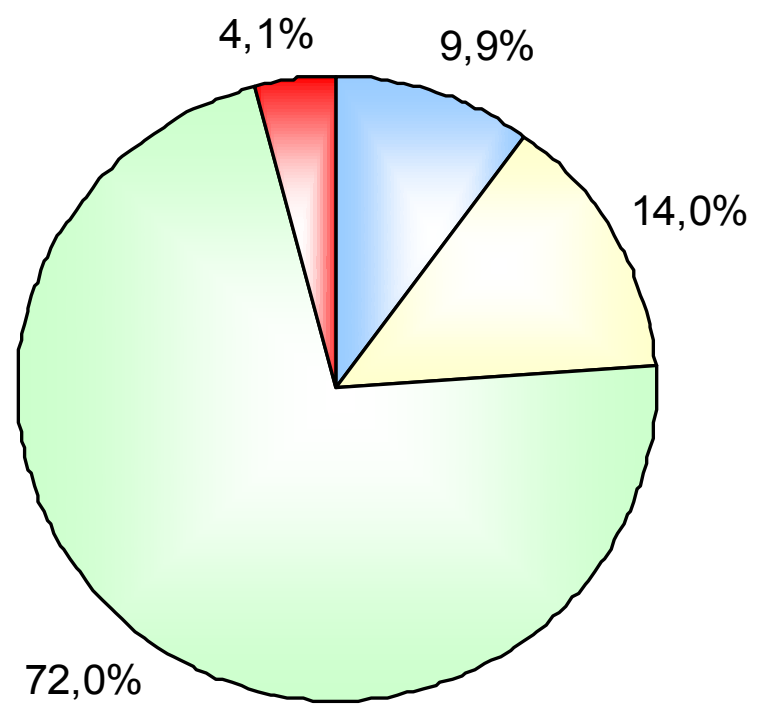

$\square$ Energéticos

$\square$ Construtores

$\square$ Reguladores

$\square$ Energéticos extras

Figura 11. Relação dos Grupos do Alimento que Menos Gosta e o Estado Nutricional de Sobrepeso e Obesidade.

Foi observado durante a coleta de dados, um desacordo no número de refeições feitas no decorrer do dia pelos sujeitos, e principalmente, o dado sobre preferências e aversões alimentares nos mostra a necessidade de uma intervenção imediata, já que é conhecido que a aderência às mudanças de hábitos alimentares é mais eficiente quanto mais precoce for a intervenção.

É importante ressaltar que, embora não tenha sido objetivo deste trabalho, observou-se que a quantidade consumida parece ser maior do que a recomendada para a faixa etária avaliada. Necessita-se de estudos futuros sobre a quantidade consumida pelas crianças e a prevalência de sobrepeso/obesidade, para se obter mais informações sobre a alimentação dessas crianças. 


\section{CONCLUSÕES}




\section{CONCLUSÕES}

De acordo com os objetivos propostos os resultados obtidos apontam tendências e algumas confirmações.

Conclui-se que a amostra estudada já apresenta sobrepeso e obesidade em níveis elevados (principalmente nos indivíduos das escolas particulares), o que causa preocupação com esta doença.

O trabalho representa a população de escolares de Franca, que, semelhante à população brasileira, vem passando por uma modificação na característica nutricional e conseqüentemente cultural, com diminuição de desnutrição passando para uma população com excessos nutricionais, direcionando-se para população obesa.

Outro ponto importante é a associação do nível sócioconomico com o sobrepeso e a obesidade nas crianças; os alunos das escolas particulares são os mais propensos ao sobrepeso/obesidade seguidos dos das escolas estaduais e por último das municipais.

A freqüência de atividade física é baixa independente do estado nutricional e do tipo de escola que as crianças estudam, mas observou-se que os alunos das escolas estaduais são os que mais realizam atividades físicas, independentemente do sexo. Porém apenas 9,1\% das crianças com sobrepeso/obesidade realizam atividade física adequadamente em relação à freqüência.

O tipo de atividade física recreacional e o tempo que as crianças desempenham essas funções, não foram associados com sobrepeso/obesidade; porém as crianças com essa classificação realizam atividades recreacionais menos ativas se comparado aos eutróficos e baixo peso. 
O hábito alimentar não se mostrou associado ao sobrepeso/obesidade, provavelmente porque neste estudo decidiu-se avaliar a qualidade dos alimentos ingeridos e não a quantidade. Para se avaliar esse dado um novo estudo deverá ser realizado, levando em consideração fatores de interferência como a idade dos sujeitos ou a escolaridade dos responsáveis que possivelmente responderiam ao questionário alimentar.

A informação que a maioria das crianças prefere em sua alimentação os alimentos fontes de energia extra e relatam gostar menos daqueles que são fontes de vitaminas, sais minerais e fibras, traz uma grande preocupação, embora o relato da preferência ou da aversão não comprove que o consumo destes alimentos sejam freqüentes ou ausentes na alimentação habitual dos sujeitos. Esse dado, se comparando os sujeitos com excesso de peso com o total dos sujeitos pesquisados, é bastante semelhante, ou seja, parece não haver diferença entre a preferência e a aversão entre obesos e não obesos.

Torna-se necessário então, desenvolver um programa de incentivo à prática de atividade e de reeducação alimentar com as crianças estudadas e suas respectivas famílias, com o objetivo de reduzir as taxas de obesidade encontradas e prevenir sua instalação nesta população, trazendo as conseqüências já apresentadas para a saúde.

Segundo o Ministério da Saúde (2005), o setor público precisa assumir a responsabilidade de iniciar mudanças sócio-ambientais, em nível coletivo, para favorecer as escolhas saudáveis no nível individual. Quando a sociedade, o setor produtivo e o setor público se juntarem para compartilhar a responsabilidade este pode ser o caminho para a construção de modos de vida que tenham como objetivo central a promoção da saúde e a prevenção das doenças. 
Assim, a promoção da alimentação saudável amplia a autonomia decisória por meio do acesso à informação para a escolha e adoção de práticas de vida e/ou alimentares saudáveis. 
REFER $\hat{E N C I A S}$ 


\section{REFERÊNCIAS}

ALMEIDA, S. S.; NASCIMENTO, P. C. B. D.; QUAIOTI, T. C. B. Quantidade e qualidade de produtos alimentícios anunciados na televisão brasileira. Rev Saúde Públ., São Paulo, v. 36, n. 3, p. 353-5, 2002.

ALVES, J. G. B. Atividade física em crianças: Promovendo a saúde do adulto. Rev. Bras. Saúde Materno Infantil, Recife, v. 3, n. 1, p. 5-6, jan-mar 2003.

ATKINSON, R. L. Introdução à Psicologia. 11ed. Porto Alegre: Artes Médicas, 1995. 727p.

BATISTA-FILHO, M., RISSIN, A. A transição nutricional no Brasil: tendências regionais e temporais. Cad. Saúde Pública, Rio de Janeiro, v. 9, supl.1, 2003.

BERKEY C. S.; ROCKETT H. R.; FIELD A. E.; GILLMAN M. W.; FRAZIER A. L.; CAMARGO JÚNIOR, C. A.; COLDITZ G. A. Activity, dietary intake, and weight changes in a longitudinal study of preadolescent and adolescent boys and girls. Pediatrics, v. 105, n. 4, p. 56, 2000. Disponível em: http:// pedriatcs.aappublication.org/cgi/reprint/105/4/e56. Acesso em maio de 2006.

BONOMO, E.; CAIAFFA, W. T. CÉSAR, C. C.; LOPES, A. C. S.; LIMACOSTA, M. F. Consumo alimentar da população adulta segundo perfil sócioconomico e demográfico: Projeto Bambuí. Cad. Saúde Pública, Rio de Janeiro, v. 19, n. 5, p. 1461-71, set-out, 2003. 
BRAY, G. A; POPKIN, B. M. Dietary fat intake does affect obesity. Am J Clin Nutr, Bethesda, n. 68, p. 1157-73, 1998.

CABALLERO, B.; DAVIS, S.; DAVIS, C. E.; ETHELBAH, B.; EVANS, M.; LOHMAN, T.; STEPHENSON, L.; STORY, M.; WHITE, J. Pathways: A school-based program for the primary prevention of obesity in American Indian children. J. Nutr. Biochem, New York, v. 9, p. 535 - 543, 1998.

CENTER OF DISEASE CONTROL - US Departament of Health and Human Services Center of Disease Control - Epi-Info 6.0 - Um Sistema de Processamento de texto, banco de dados e estatística para epidemiologia em microcomputadores, 1994.

CERQUeIRA, E. M. M.; OliveIRA, A. M. A.; OliVeIRA, A. C. Prevalência de sobrepeso e obesidade infantil na cidade de Feira de Santana-BA: detecção na família $x$ diagnóstico clínico. Jornal de Pediatria. Rio de Janeiro, v. 79, n. 4, 2003. Disponível em: http://www.scielo.com. Acesso em abril de 2006.

DIETZ, W. H. Prevention of childhood obesity. Pediatr Clin North Am, v. 33, p. 823-33, 1986.

DOYLE, E. I.; FELDMAN, R. H. L. Preferências nutricionais entre adolescentes da classe média de Manaus, AM (Brasil). Rev. Saúde Pública, São Paulo, v. 31, n. 4, p. 342-350, 1997. 
ESCRIVÃO, M. A. M. S.; OLIVEIRA, F. L. C; TADDEI, J. A. A. C.; LOPEZ, F. A. Obesidade exógena na infância e na adolescência. Jornal de Pediatria, Rio de Janeiro, v. 76, supl. 3, S305, 2000.

FISBERG, M. Atualização em obesidade na infância e na adolescência. São Paulo: Editora Atheneu, 2004, 218p.

FRANCISCHI, R. P. P.; PEREIRA, L. O.; FREITAS, C. S.; KLOPFER, M.; SANTOS, R. C.; VIEIRA, P.; LANCHA-JÚNIOR, A. H. Obesidade: Atualização sobre Etiologia, Morbidade e Tratamento. Rev. Nutr. Campinas, v. 13, n. 1, p. 17-29, jan./abr.2000.

FRISANCHO, A. R. Anthropometric standards for the assessment of growth and nutritional status. Ann. Arbor, Mich, University of Michigan Press, 1990.

GIUGLIANO, R.; MELO, A. L. P. Diagnóstico de sobrepeso e obesidade em escolares: utilização do índice de massa corporal segundo padrão internacional. Jornal de Pediatria, Rio de Janeiro, v. 80, n. 2, p.129-134, 2004.

GUERRA, S.; OLIVEIRA, J.; RIBEIRO, J. C.; TEIXEIRA-PINTO, A.; DUARTE, J. A.; MOTA, J. Relação entre atividade física regular e a agregação de fatores de risco biológicos das doenças cardiovasculares em crianças e adolescentes. Rev. Bras. Saúde Materno Infantil, Recife, v. 3, n. 1, p. 9-15, jan-mar 2003. 
IBGE. Pesquisa de Orçamento Familiar - POF 2002-2003. Antropometria e Análise do Estado Nutricional de Crianças e Adolescentes no Brasil. 2006. Disponível em:

http://ibge.gov.br/home/estatistica/populacao/condicaodevida/pof/2003medid as/pof2003medidas/pdr. Acesso em: junho de 2006.

KAHTALIAN, A. Obesidade: um desafio. Revista Psicossomática Hoje, p. 273-278, 1992.

KUSHI, L. H.; FOLSOM, A. R.; JACOBS, D. R.; LUERPKER, R. V.; ELMER, P. J.; BLACKBURN, H. Educational attainment and nutrient consumption patters: The Minnesota Heart Survey. J. Am. Dietetic Association, Bethesda, v. 88, p. 1230-36, 1988.

LOGUE, A. W. The psychology of eating and drinking: An introduction. 2 ed. New York: Freeman. 1991, p. 383; 390; 392; 415.

MAHAN, L. K.; ESCOTT-STUMP, S. Krause: Alimentos, Nutrição e Dietoterapia. 9 ed. São Paulo: Roca, 1998, 1179p.

MARINHO, S. P; MARTINS, I.S.; PERESTRELO, J. P. P.; OLIVEIRA, D. C. Obesidade em adultos de segmentos pauperizados da sociedade. Rev. Nutr., Campinas, v. 16, n. 2, p. 195-201, abr./jun. 2003. 
MELLO, E. D; LUFT, V. C; MEYER, F. Obesidade infantil: como podemos ser eficazes? Jornal de Pediatria, Rio de Janeiro, v. 80, n.3, p. 173-182, maio/jun 2004.

MINISTÉRIO DA SAÚDE. O que é uma alimentação saudável? Considerações sobre o conceito, princípios e características: uma abordagem ampliada. maio, 2005. Disponível em: http://dtr2004.saude.gov.br/nutricao/documentos/o_que_e_alimentacao_sau davel.pdf. Acesso em maio de 2006.

MINISTÉRIO DO TRABALHO E EMPREGO. Classificação Brasileira de Ocupações (CBO). 2002. Disponível em: http://www.mtecbo.gov.br/. Acesso em maio de 2005.

MONTEIRO, C. A. (Org.) Velhos e Novos Males da Saúde no Brasil: a Evolução do país e suas Doenças. 2ed. Revisada e aumentada. São Paulo: Hucitec, Nupens/USP, 2000. p. 247-55.

NATIONAL CENTER FOR HEALTH STATISTICS (NCHS)/ CENTERS OF DISEASE CONTROL AND PREVENTION (CDC). Growth Charts: United States. Advance Data, n. 314. Dec 4, 2000. Disponível em http://www.cdc.gov-nchs-data-ad-ad314.pdf Acesso em 2005.

OLIVEIRA, C. L; FISBERG, M. Obesidade na infância e adolescência - Uma verdadeira epidemia, Arq Bras Endocrinol Metab, São Paulo, v. 47, n. 2, p. 107-108, abril 2003. 
OLIVEIRA, F. L. C.; ESCRIVÃO, M. A. M. S.; ANCONA-LOPEZ, F. Obesidade exógena na infância e na adolescência. Rev. Diagnóstico e Tratamento. v. 5, n. 2, p. 39-42, abr/mai/jun 2000.

ORGANIZAÇÃO MUNDIAL DE SAÚDE. Estratégia Global em Alimentação Saudável, Atividade Física e Saúde. In: ASSEMBLÉIA MUNDIAL DE SAÚDE, 57. 2004, Genebra, 23p. Tradução não oficial realizada pela CGPAN/MS: 2006. Disponível em:

http://dtr2004.saude.gov.br/nutricao/documentos/eb_portugues.pdf. Acesso em maio de 2006.

PERL, M. A.; MANDIC, M. L.; PRIMORAC, L.; KLAPEC, T.; PERL, A. Adolescent Acceptance of Different Foods by Obesity Status and by Sex. Physiology \& Bechavior, v. 65, n. 2, p. 241-245, 1998.

RODIN, M. Current status of the internal-external hypothesis of obesity: What went wrong? American Psychologist, v. 36, p. 361-372, 1981.

ROLLAND-CACHERA, M. F., DEHEEGER, M.; BELLISLE, F.; SEMPE, M.; GUILLOUD-BATAILLE, M.; PATOIS, E. Adiposity rebound in children: a Simple indicator for predicting obesity. Am. J. Clin Nutr, , Bethesda, v. 39, n.1, p. 129, 1984.

ROSENBAUM M., LEIBEL R.L. The physiology of body weigh regulation: relevance to the etiology of obesity in children. Pediatrics, Illinois, n. 101, v. 3, p. 525-39, 1998. 
SANTOS, G.V.B. Excesso de peso e seus fatores de risco em adolescentes da rede pública e privada de ensino do município de Ribeirão Preto, SP - Brasil. 2003. 193p. Tese. Escola de Enfermagem de Ribeirão Preto da Universidade de São Paulo, Ribeirão Preto, 2002.

SILVA, G. A. P; BALABAN G.; MOTTA, M. E. F. A: Prevalência de sobrepeso e obesidade em crianças e adolescentes de diferentes condições sócio-econômicas. Rev. Bras. Saúde Materno Infantil, Recife, v. 5, n. 1, jan./mar 2005. Disponível em: http://www.scielo.com. Acesso em dezembro de 2005.

SILVA, G. A. P.; BALABAN, G.; FREITAS, M. M. V.; BARACHO, J. D. S.; NASCIMENTO, E.M.M. Prevalência de sobrepeso e obesidade em crianças pré-escolares matriculadas em duas escolas particulares de Recife, Pernambuco. Rev. Bras. Saúde Materno Infantil, Recife, v. 3, n. 3, jul-set, 2003. Disponível em: http://www.scielo.com. Acesso em abril de 2006.

SOAR, C.; VASCONCELOS, F. A. G; ASSIS, M. A. A.; GROSSEMAN, S.; LUNA, M.E.P. Prevalência de sobrepeso e obesidade em escolares de uma escola pública de Florianópolis, SC. Rev. Bras. Saúde Materno Infantil, Recife, v. 4, n. 4, out/dez, 2004. Disponível em: http://www.scielo.com. Acesso em janeiro de 2006.

SOTELO, Y. O. M.; COlUGNATI, F. A. B.; TADDE, J. A. A. C. Prevalência de sobrepeso e obesidade entre escolares da rede pública segundo três critérios de diagnóstico antropométrico. Cad. Saúde Pública, Rio de Janeiro, v. 20, n. 1, jan/fev, 2004. Disponível em: http://www.scielo.com. Acesso em janeiro de 2006. 
STRAUSS, R. S. Childhood Obesity and Self-Esteem. Pediatrics, Illinois, v. 105, n. 1, p. 1-5, jan 2000.

VASCONCELOS, V. L.; SILVA, G. A. P. Prevalência de sobrepeso e obesidade em adolescentes masculinos no Nordeste do Brasil, 1980-2000. Cad. Saúde Pública, Rio de Janeiro, v. 19, n. 5, set/out 2003. Disponível em: http://www.scielo.com. Acesso em novembro de 2005.

WILLETT, W. C. Nutritional Epidemioligy. 2 ed. New York: Oxford University Press, 1998.

WIRTH, A. Non-pharmacological therapy for metabolic syndrome. Herz, Munchen, v. 20, n. 1, p. 56-69, 1995.

WORLD HEALTH ORGANIZATION. Obesity, preventing and managing the global epidemic. Defining the problem of overweight and obesity. In: REPORT OF A WHO CONSULATION ON OBESITY, Geneva, 1998. 
ANEXO

$-21 \mathrm{NLC}$ 


\begin{abstract}
ANEXO
APROVAÇÃo do COMITÊ DE ÉTICA EM PESQUISA DO CSE-FMRP
\end{abstract}

\begin{tabular}{|c|c|}
\hline $\begin{array}{c}\text { FACULDADE DE MEDICINA DE } \\
\text { RIBEIRÃO PRETO } \\
\text { UNIVERSIDADE DE SÃo } \\
\text { PAULO }\end{array}$ & $\begin{array}{c}\text { Rua Terezina, 690-CEP: 14055-380 } \\
\text { Ribeirão Preto - SP }\end{array}$ \\
$\begin{array}{c}\text { CENTRO DE SAÚDE } \\
\text { ESCOLA }\end{array}$ & $\begin{array}{c}\text { Telefone PABX }\left(0^{* * 16} 16\right) 633-2331 / 4480 \\
\text { FAX }\left(0^{* *} 16\right) 6332331\end{array}$ \\
\hline
\end{tabular}

Ribeirão Preto, 16 de abril de 2005.

OF. $N^{\circ} .153 / 05 / C O O R D . C E P / C S E-F M R P-U S P$

Senhor Professor,

Vimos na presente oportunidade comunicar que o Comitê de Ética em Pesquisa do Centro de Saúde Escola da Faculdade de Medicina de Ribeirão Preto da Universidade de São Paulo, em sua $37^{a}$ reunião ordinária, realizada em 15 de março de 2005, analisou e apreciou o parecer do Senhor Relator, referente ao Projeto de Pesquisa: "Prevalência da Obesidade Infantil em Escolas Públicas e Privadas do Ensino Fundamental da Cidade de Franca e suas interrelações com o Ambiente Escolar e os Hábitos Alimentares", Protocolo: 0141/CEP/CSE-FMRP-USP, que está sendo conduzido por V.S ${ }^{\text {a }}$ e pela orientanda Daniela Elias Goulart de Andrade, foi Aprovado. Lembramos que em atendimento à Resolução 196/96, deverá ser encaminhado a este CEP o relatório final da pesquisa e a publicação de seus resultados.

Sendo o que tínhamos para o momento, despedimo-nos.

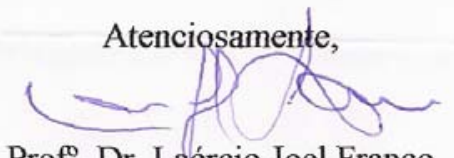

Prof ${ }^{\circ}$. Dr. Laércio Joel Franco Coordenador do CEP/CSE-FMRP-USP

Ilmo. Sr.

Prof. Dr. Amaury Lélis Dal Fabbro

Departamento de Medicina Social da FMRP-USP. 
APÊNDICES 
APÊNDICE A 
APÊNDICE B 


\title{
APÊNDICE C
}

\section{VIA DO PESQUISADO/ESCOLA}

\author{
Termo de Consentimento Livre e Esclarecido
}

Tema: "Prevalência da Obesidade Infantil em Escolas Públicas e Privadas do Ensino Fundamental da Cidade de Franca e suas interrelações com o Ambiente Escolar e os Hábitos Alimentares”

Prezado senhor (a)

Eu, Daniela Elias Goulart de Andrade, nutricionista, registrada no Conselho Regional de Nutrição da $3^{\text {a }}$ Região sob o número 12.514 , estou fazendo um trabalho de pesquisa sobre Obesidade Infantil, cuja incidência tem aumentado e se tornou um grave problema de saúde pública. A finalidade é de analisar a relação dessa doença com o ambiente escolar e os hábitos alimentares das crianças com idades entre 07 e 10 anos, através de questionamentos aos indivíduos (crianças) matriculados em escolas municipais, estaduais e particulares de Franca - SP. Esta pesquisa é composta por uma avaliação antropométrica e por um questionário com 20 perguntas feitas por mim ou entrevistadores devidamente treinados, de forma sigilosa, sempre. Se o senhor (a) aceitar que seu filho (a) participe desta pesquisa, ele (a) terá que ser submetido ao exame antropométrico (aferição de peso e altura) e responder ao questionário que avalia o hábito alimentar, e, caso queira, será esclarecido quanto à evolução da pesquisa durante sua elaboração e execução. O senhor (a) tem toda a liberdade de não autorizar a participação do seu filho nesta pesquisa, bem como, a qualquer momento retirar-se da mesma, sem nenhum constrangimento. Mesmo mediante a sua autorização, seu filho pode recusar-se a participar e também nenhum constrangimento será permitido.

O nome de seu filho (a) nunca aparecerá em nenhum relatório ou trabalho resultante desta pesquisa.

Se o senhor (a) concordar em participar, por favor, assine o termo abaixo.

$\mathrm{Eu}$, após receber informações da pesquisa sobre a prevalência de obesidade infantil e os fatores que a influencia, concordo com que meu filho (a) participe da mesma. Autorizo a utilização e a divulgação dos resultados obtidos no estudo, em aulas, jornais, ou outros meios de divulgação, desde que o nome dele (a) não seja revelado a ninguém.

de de 2005.

Pesquisadora:

Daniela Elias Goulart de Andrade

Fone: 3911-7713. 


\section{VIA DO PESQUISADOR}

Termo de Consentimento Livre e Esclarecido

Tema: "Prevalência da Obesidade Infantil em Escolas Públicas e Privadas do Ensino Fundamental da Cidade de Franca e suas interrelações com o Ambiente Escolar e os Hábitos Alimentares”

Prezado senhor (a)

Eu, Daniela Elias Goulart de Andrade, nutricionista, registrada no Conselho Regional de Nutrição da $3^{\text {a }}$ Região sob o número 12.514, estou fazendo um trabalho de pesquisa sobre Obesidade Infantil, cuja incidência tem aumentado e se tornou um grave problema de saúde pública. A finalidade é de analisar a relação dessa doença com o ambiente escolar e os hábitos alimentares das crianças com idades entre 07 e 10 anos, através de questionamentos aos indivíduos (crianças) matriculados em escolas municipais, estaduais e particulares de Franca - SP. Esta pesquisa é composta por uma avaliação antropométrica e por um questionário com 20 perguntas feitas por mim ou entrevistadores devidamente treinados, de forma sigilosa, sempre. Se o senhor (a) aceitar que seu filho (a) participe desta pesquisa, ele (a) terá que ser submetido ao exame antropométrico (aferição de peso e altura) e responder ao questionário que avalia o hábito alimentar, e, caso queira, será esclarecido quanto à evolução da pesquisa durante sua elaboração e execução. O senhor (a) tem toda a liberdade de não autorizar a participação do seu filho nesta pesquisa, bem como, a qualquer momento retirar-se da mesma, sem nenhum constrangimento. Mesmo mediante a sua autorização, seu filho pode recusar-se a participar e também nenhum constrangimento será permitido.

O nome de seu filho (a) nunca aparecerá em nenhum relatório ou trabalho resultante desta pesquisa.

Se o senhor (a) concordar em participar, por favor, assine o termo abaixo.

$\mathrm{Eu}$, após receber informações da pesquisa sobre a prevalência de obesidade infantil e os fatores que a influencia, concordo com que meu filho (a) participe da mesma. Autorizo a utilização e a divulgação dos resultados obtidos no estudo, em aulas, jornais, ou outros meios de divulgação, desde que o nome dele (a) não seja revelado a ninguém.

de de 2005.

Pesquisadora:

Daniela Elias Goulart de Andrade

Fone: 3911-7713. 


\section{APÊNDICE D}

\section{Questionário}

Nome

Data: Identificação:

Data de nascimento:

Peso:

Escola: érie: dade: Altura:

Classificação do estado nutricional:

Para as Meninas: Você já mestruou? Sim Não

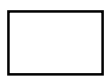

1) Qual a escolaridade do seu pai? (última série completa)

1) analfabeto

2) ensino básico

3) ensino fundamental

4) ensino médio

5) ensino superior

2) O que o “chefe” de família faz? (ocupação)

1)

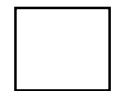

2)

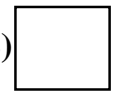

1) trabalhador manual desqualificado

2) trabalhador manual qualificado

3) trabalhador técnico

4)

5)

3) Quantas pessoas moram na sua casa contando com você? (perguntar quem são para confirmar).

1) 1

2) 2

3) 3

4) 4

5) 5 ou mais

4) Quantos são adultos? (tem mais de 18 anos).

1) 1

2) 2

3) 3

4) 4

5) 5 ou mais

5) Destes, quantos trabalham? (possuem renda própria)

1) 1

2) 2

3) 3

4) 4

5) 5

6) 6 ou mais

6) Contando com a aula de educação física ( 1 x /semana), você faz mais alguma atividade física? Que atividade é essa?

3)

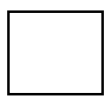

4)

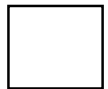

5)

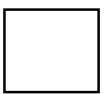

1) Não

2) futebol

3) natação

4) vôlei

5) tênis

6) dança

7) outras

Quais? 
7) Com que freqüência?

1) Não

7)

2) $1 x /$ semana

3) $2 x /$ semana

4) $3 x /$ semana

5) $4 x /$ semana

6) $5 x /$ semana ou mais

8) Nos momentos de folga, que você não está na escola, que atividades você mais realiza?

1) brinca na rua

2) brinca dentro de casa

3) joga videogame ou computador

4) assiste tv

5) arruma a casa

6) trabalha

7) outros

9) Quanto tempo por dia você realiza essas atividade?

1) menos de 30 minutos

2) $30 \mathrm{~min}$. a 1 hora

3) 1 hora a 2 horas

4) 2 horas a 3horas

5) mais de 3 horas

10) Quanto de água você bebe no dia?

1) menos de $500 \mathrm{ml}$ (até 2 copos de requeijão)

2) entre 500 e $1000 \mathrm{ml}$ (3 - 4 copos de requeijão)

3) entre 1000 e $1500 \mathrm{ml}$ ( 5 - 6 copos de requeijão)

4) entre 1500 e $2000 \mathrm{ml}$ ( 7 - 8 copos de requeijão)

5) mais de $2000 \mathrm{ml}$ (mais de 8 copos de requeijão)

11) Qual é seu Alimento preferido? (primeiro a ser respondido)

9)

8)

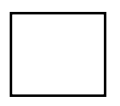

1) grupo dos energéticos 3 3) grupo dos reguladores

2) grupo dos construtores $\quad 4$ ) grupo dos energéticos extras

12) Qual é o Alimento que não gosta? (primeiro a ser respondido)

1) grupo dos energéticos

2) grupo dos construtores

3) grupo dos reguladores

4) grupo dos energéticos extras

Quais as refeições que você costuma fazer?

\begin{tabular}{|l|l|l|}
\hline \multicolumn{1}{|c|}{ REFEIÇÕES } & (1) sim & \multicolumn{1}{c|}{ (2) não } \\
\hline 13) café da manhã & & \\
\hline 14) colação & & \\
\hline 15) almoço & & \\
\hline 16) lanche da tarde & & \\
\hline 17) jantar & & \\
\hline 18) ceia & & \\
\hline Outra? & & \\
\hline Quais? & & \\
& & \\
\hline
\end{tabular}


Recordatório alimentar de 24h:bn

O que você comeu ontem?

19) No café da manhã?

20) Na colação? (lanche da manhã)

21) No almoço?

22) Lanche da tarde?

23) No jantar?

24) Antes de dormir? (ceia)

25) Outras? 